\title{
Lithium-Responsive Seizure-Like Hyperexcitability Is Caused by a Mutation in the Drosophila Voltage-Gated Sodium Channel Gene paralytic
}

\author{
(D) Garrett A. Kaas, ${ }^{1}$ Junko Kasuya, ${ }^{2}$ Patrick Lansdon, ${ }^{1}$ Atsushi Ueda, ${ }^{3}$ Atulya lyengar, ${ }^{4}$ Chun-Fang \\ $\mathrm{Wu}^{1,3,4}$ and ${ }^{1}$ Toshihiro Kitamoto ${ }^{1,2,4}$
}

DOI:http://dx.doi.org/10.1523/ENEURO.0221-16.2016

${ }^{1}$ Interdisciplinary Graduate Program in Genetics, University of lowa, IA 52242, USA, ${ }^{2}$ Department of Anesthesia, Carver College of Medicine, University of lowa, IA 52242, ${ }^{3}$ Department of Biology, College of Liberal Arts and Sciences, University of lowa, IA 52242, and ${ }^{4}$ Interdisciplinary Graduate Program in Neuroscience, University of lowa, IA 52242

\begin{abstract}
Shudderer (Shu) is an X-linked dominant mutation in Drosophila melanogaster identified more than 40 years ago. A previous study showed that Shu caused spontaneous tremors and defects in reactive climbing behavior, and that these phenotypes were significantly suppressed when mutants were fed food containing lithium, a mood stabilizer used in the treatment of bipolar disorder (Williamson, 1982). This unique observation suggested that the Shu mutation affects genes involved in lithium-responsive neurobiological processes. In the present study, we identified Shu as a novel mutant allele of the voltage-gated sodium $\left(\mathrm{Na}_{\mathrm{v}}\right)$ channel gene paralytic (para). Given that hypomorphic para alleles and RNA interference-mediated para knockdown reduced the severity of Shu phenotypes, Shu was classified as a para hypermorphic allele. We also demonstrated that lithium could improve the behavioral abnormalities displayed by other $\mathrm{Na}_{v}$ mutants, including a fly model of the human generalized epilepsy with febrile seizures plus. Our electrophysiological analysis of Shu showed that lithium treatment did not acutely suppress $\mathrm{Na}_{v}$ channel activity, indicating that the rescue effect of lithium resulted from chronic physiological adjustments to this drug. Microarray analysis revealed that lithium significantly alters the expression of various genes in Shu, including those involved in innate immune responses, amino acid metabolism, and oxidationreduction processes, raising the interesting possibility that lithium-induced modulation of these biological pathways may contribute to such adjustments. Overall, our findings demonstrate that $\mathrm{Na}_{\mathrm{v}}$ channel mutants in Drosophila are valuable genetic tools for elucidating the effects of lithium on the nervous system in the context of neurophysiology and behavior.
\end{abstract}

Key words: Drosophila; lithium; neurogenetics; seizure; voltage-gated sodium channel

\section{Significance Statement}

The alkaline metal lithium has been used as one of the most effective mood-stabilizing agents for bipolar disorder for more than 60 years. Although a number of molecular targets for lithium have been proposed, the neural mechanisms underlying lithium action still remain unclear. Here we show that lithium treatment significantly reduced the severity of seizure-like hyperexcitability displayed by hypermorphic alleles of the Drosophila $\mathrm{Na}_{v}$ channel gene. Our studies indicate that suppression of mutant phenotypes is achieved through lithium-induced physiological adjustments, leading to compensation of defects caused by mutated $\mathrm{Na}_{\mathrm{v}}$ channels. These findings provide novel insight into the effects of the mood-stabilizing agent lithium on neural function and behavior and may ultimately contribute to a clearer understanding of lithium-responsive disorders in humans. 


\section{Introduction}

Since the initial discovery in 1949 that lithium possesses mood-stabilizing properties (Cade, 1949), the alkali metal has remained one of the most widely used medications for bipolar disorder (BPD). Over the years, various hypotheses have been proposed to explain the physiological effects of lithium. These stem mainly from lithium's ability to inhibit, either directly or indirectly, particular enzymes such as glycogen synthase kinase $3 \beta$ (GSK-3 $\beta$; Klein and Melton, 1996), inositol monophosphatase (IMPase), and inositol 1-polyphosphate phosphatase (IPPase; Berridge et al., 1989; Shastry, 1997). By inhibiting these enzymes, lithium is thought to alter the signaling cascades in which they participate, ultimately influencing an array of physiological processes (Manji and Lenox, 1998; Phiel and Klein, 2001; Lenox and Wang, 2003; Machado-Vieira et al., 2009). However, the exact mechanisms by which lithium modifies neural function and improves pathophysiological behaviors are still not fully understood.

Studies using animal models suggest that the effects of lithium on the nervous system have common features across a range of diverse animal species. In particular, the fruit fly Drosophila melanogaster displays a neurobiological response to lithium resembling that observed in mammals. For instance, chronic treatment with lithium lengthens the free-running period of the circadian rhythm in both mice and fruit flies (Padiath et al., 2004; Dokucu et al., 2005; litaka et al., 2005). Likewise, lithium can protect against polyglutamine-induced neurotoxicity in Drosophila (Berger et al., 2005), as is observed in rodent models of Huntington's disease (Wei et al., 2001; Senatorov et al., 2004). Furthermore, lithium treatment can rescue the behavioral deficits exhibited by the Drosophila fragile $X$ mental retardation 1 (dfmr1) mutant, as was observed in human fragile $X$ patients and rodent models of the disease (McBride et al., 2005; Berry-Kravis et al., 2008; Yuskaitis et al., 2010). These findings indicate that studies in Dro-

Received August 1, 2016; accepted October 6, 2016; First published October 27, 2016.

The authors declare no conflict of interest.

Author Contribution: G.A.K., J.K., C.-F.W., and T.K. designed research; G.A.K., J.K., P.A.L., A.U., A.I., and T.K. performed research; G.A.K., J.K., A.U., A.I., C.-F.W., and T.K. analyzed data; G.A.K., J.K., A.U., A.I., C.-F.W., and T.K. wrote the paper.

This study was supported by NIH grants (R03MH62684/R01MH085081 to T.K., R01GM088804/R01GM080255 to C.-F.W., F31MH081788 to G.K., F31NS082001 to A.I., and T32NS045549 to P.L.)

Garrett A. Kaas's present address: Department of Pharmacology, Vanderbilt University School of Medicine, Nashville, TN 37232.

Acknowledgements: We thank Dr. Mark Tanouye (University of California, Berkeley), Dr. Diane O'Dowd (University of California, Irvine), the Bloomington Drosophila Stock Center, and the Vienna Drosophila RNAi Center for providing fly strains. We also thank Mr. Ryan Jewell (currently at the University of Texas M.D. Anderson Cancer Center) for his assistance in recombination mapping as well as members of the Kitamoto and Wu labs for helpful discussion.

Correspondence should be addressed to Toshihiro Kitamoto, 1-316 BSB, 51 Newton Road, lowa City, IA 52242. E-mail: toshi-kitamoto@uiowa.edu.

DOI:http://dx.doi.org/10.1523/ENEURO.0221-16.2016

Copyright @ 2016 Kaas et al.

This is an open-access article distributed under the terms of the Creative Commons Attribution 4.0 International, which permits unrestricted use, distribution and reproduction in any medium provided that the original work is properly attributed. sophila can provide valuable insights into the basic mechanisms of lithium action on neural function and behavior.

Shudderer (Shu) was originally isolated more than 40 years ago, through an ethyl methanesulfonate mutational screen in Drosophila (Williamson, 1971), as an X chromosome-linked dominant mutation that causes sporadic jerks and defects in reactive climbing behavior (Williamson, 1982). Interestingly, Williamson reported that these behavioral phenotypes were significantly suppressed when adult Shu mutants were fed a diet supplemented with lithium salts (Williamson, 1982). This finding implied that the Shu mutation affects genes related to lithiumresponsive neurobiological processes. To our knowledge, however, no research on Shu has followed since the original report in 1982, and this mutation remains to be characterized at both the molecular and functional levels. In the present study, we have identified Shu as a hypermorphic mutation in the Drosophila voltage-gated sodium $\left(\mathrm{Na}_{\mathrm{v}}\right)$ channel gene paralytic (para) and found that lithium also mitigates behavioral phenotypes of some other para mutants. A combination of molecular, pharmacological, electrophysiological, and behavioral analyses from our study suggests that lithium's suppressive effect on Shu phenotypes is not due to acute actions of the drug but rather through long-term physiological adjustments to lithium treatment. Our results connecting lithium with $\mathrm{Na}_{v}$ channel dysfunction demonstrate that Shu and other $\mathrm{Na}_{v}$ channel mutants in Drosophila are valuable genetic tools for investigating the effects of lithium on the nervous system in the context of neurophysiology and behavior.

\section{Materials and Methods}

\section{Fly stocks and culture conditions}

Fly cultures were reared at $25^{\circ} \mathrm{C}$ in a 12 -h light/dark cycle on a conventional cornmeal/glucose/yeast/agar medium supplemented with the mold inhibitor methyl 4-hydroxybenzoate $(0.05 \%)$. Flies used for electrophysiological experiments were raised on a fly food formulation described previously (Frankel and Brousseau, 1968). The Canton-S strain (CS) was used as the wild-type control. Shu (Williamson, 1982) was obtained as Shu/FM6 from Rodney Williamson (Beckman Research Institute of the City of Hope, Duarte, CA). The original Shu mutants were outcrossed to the $C S$ line at least 26 times and balanced with FM7-Actin-GFP. Shu/FM7-Actin-GFP females were crossed to CS, and the resultant Shu/ + flies were used for most experiments in this study. The RNAi lines $w^{1118}$; P[UAS-para-RNAl] (GD6131 and GD6132) and $w^{1118}$ control were obtained from the Vienna Drosophila Resource Center, Vienna. The following P-element lines were obtained from the Bloomington Drosophila Stock Center, Bloomington, IN: $y^{1} w^{67023}$ P[EPgy2]Axs ${ }^{\text {YYO00887 }} ; y^{1}$ $w^{67 c 23} P[E P g y 2] C a n A-14 F^{E Y 08594} ; y^{1} w^{67 c 23} P$ P[EPgy2] CG9902 ${ }^{\text {EY05861; }} y^{1} w^{67 c 23} P[E P g y 2] R b p 2^{\text {EY00852 }} ; y^{1} w^{67 c 23}$ P[EPgy2]CG4239 ${ }^{\text {EY01983 }}, y^{1} w^{67 c 23}$ P[EPgy2]eas ${ }^{E Y 01463}, y^{1}$ $w^{67 c 23} P[E P g y 2] C a n A-14 F^{E Y 09066}$, and $y$ w P[GawB]NP6106/ $F M 7 c$. Other fly strains used in this study were obtained from the following sources: para ${ }^{\text {bss } 1}$ from Dr. Mark Tanouye (University of California, Berkeley, CA); para ${ }^{G E F S+}, p^{2} a^{D S}$, and 
their control from Dr. Diane O'Dowd (University of California, Irvine, CA).

\section{Mapping procedure}

Meiotic recombination mapping of the Shu mutation was conducted using molecularly defined P-element insertion lines as described in Zhai et al. (2003). Briefly, a white $(w)$ mutation was first introduced into the Shu chromosome ( $w S h u$ ), which was balanced with w FM7. In the F1 generation, virgin female flies trans-heterozygous for $w$ Shu and a P-element insertion ( $w$ Shu/w $P$ ) were crossed to $w$ males. In the F2 generation, recombinants were identified as Shu mutants with orange eyes ( $w$ Shu $P / w$ or w $P$ Shu/w) or non-Shu flies with white eyes $(w / w)$. The projected molecular position was calculated from the percentages of recombinants and the insertion sites of P-elements in base pairs between each combination of $\mathrm{P}$-element pairs flanking either side of the projected lesion site established from earlier mapping (Zhai et al., 2003).

\section{Behavioral analyses \\ Shuddering}

Newly eclosed virgin Shu and CS females were collected under $\mathrm{CO}_{2}$ anesthesia. To eliminate possible effects of downturned wings on shuddering assays, wings of the mutant and control flies were cut with microdissecting scissors (Ladd Research, Williston, VT). Fly cultures were kept and tested in an environmental chamber at $25^{\circ} \mathrm{C}$ and $60-70 \%$ humidity. Flies were individually placed into standard mating chambers $(15-\mathrm{mm}$ diameter, $3-\mathrm{mm}$ depth) using a manual aspirator and allowed to acclimate for $5 \mathrm{~min}$. At the end of $5 \mathrm{~min}$, fly behavior was video recorded (DCR-PC300; Sony, Tokyo) for $2 \mathrm{~min}$. Shu and wild-type flies were scored for the number of times that a strong convulsive episode flipped the fly onto its back. The scoring investigators were blinded to the experimental treatments. At least 30 flies were used for each treatment, genotype, and time point tested.

\section{Reactive climbing}

The reactive climbing assay was performed as previously described (Greene et al., 2003) using a countercurrent apparatus originally invented by Seymour Benzer for analyzing phototaxis behaviors (Benzer, 1967). Briefly, virgin females of each genotype were collected shortly after eclosion. To ensure that climbing was not affected by the downturned wing phenotype of Shu mutants, wings of the mutant and control flies were cut with microdissecting scissors. Flies were aged in groups of $\sim 20$. At the time of the experiment, they were placed into one tube (tube 0), tapped to the bottom, and allowed $15 \mathrm{~s}$ to climb, at which point the flies that had climbed were transferred to the next tube. This process was repeated a total of five times. After the fifth trial, the flies in each tube $(0-5)$ were counted. The climbing index was calculated using the following formula: $\mathrm{Cl}=\Sigma\left(N_{i} \times i\right) /\left(5 \times \Sigma N_{i}\right)$, where $i$ and $N_{i}$ represent the tube number $(0-5)$ and the number of flies in the corresponding tube, respectively. At least five groups were tested for each genotype or treatment.

\section{Video tracking locomotor analysis}

Newly eclosed virgin females were collected and aged for $5 \mathrm{~d}$. Flies were individually placed into standard mating chambers using a manual aspirator and allowed to acclimate for $5 \mathrm{~min}$. At the end of $5 \mathrm{~min}$, fly behavior was recorded using a web camera (Logicool Quickcam IM, Logitech, Fremont, CA). Images of individual flies were captured at 15 frames/s for 10 min and analyzed using pySolo (Gilestro and Cirelli, 2009) to track fly locomotion and compute $x, y$ coordinates during every frame for a total of 9000 frames. The percentage of time a fly spent inside an inner circle $(70 \%$ diameter of the chamber) during the 10-min observation period was calculated from its $x, y$ coordinates.

\section{Ether-induced shaking}

Five-d-old flies of the indicated genotypes were introduced into a Drosophila etherizer (Science Kit \& Boreal Laboratories, Tonawanda, NY) and exposed to a saturated dose of diethyl ether for $10 \mathrm{~s}$. A drop of adhesive was then applied to the posterior dorsal thorax of each fly and fixed to a piece of plain white paper in a $35 \times 10-\mathrm{mm}$ Petri dish. Flies were then allowed to recover for 2-3 min before video recording using a Quickcam connect camera (Logitech) mounted on a Leica MZFLIII stereoscope (Leica Microsystems, Bannockburn, IL). Images were captured at $15 \mathrm{frames} / \mathrm{s}$ for $1 \mathrm{~min}$ and analyzed using pySolo to generate $x, y$ data. Head movement was tracked by generating a mask (i.e., cropping out the entire image outside the selected area) and focusing on the anterior lateral region of the eye and the background. This area was selected based on initial trials, which indicated it to be the most consistent region in which to track head movement without picking up antennal motion. Leg movement was tracked by producing a mask selection encompassing the joint between the tibia and tarsus of the hind leg. Special care was taken to use video only where no other appendages or body parts entered the tracking mask during the 1-min recording. Velocities of both the head and leg movements between frames were calculated using Microsoft Excel.

\section{Heat-induced seizure}

Heat-induced seizure assay was performed as described in Sun et al. (2012) using 5-d-old flies. Individual flies were isolated in a glass vial $(15 \times 45 \mathrm{~mm})$ and acclimated for $15-30 \mathrm{~min}$. The vials were submerged in a water bath set at either $37^{\circ} \mathrm{C}$ or $40^{\circ} \mathrm{C}$ for 2 min. At 5 -s intervals, the status of individual flies was determined to be either seizing or not seizing, and the proportion of flies seizing at each time point was calculated. Heat-induced seizures were defined as a period of leg twitches, failure to maintain standing, wing flapping, or abdominal curling (Sun et al., 2012).

\section{Heat-induced paralysis}

Individual flies were isolated in a glass vial $(15 \times 45 \mathrm{~mm})$ and acclimated for 10-15 min. Vials were submerged in a water bath set at $34^{\circ} \mathrm{C}$ and monitored for paralysis. Paralysis was defined as cessation of movement and/or loss of posture. 


\section{Bang sensitivity recovery assay}

Individual flies were isolated in a glass vial $(15 \times 45 \mathrm{~mm})$ and acclimated for 15-30 min. Flies were subjected to 10 $s$ of mechanical shock delivered by a vortex at maximum intensity. The time to recover, defined as a return to a standing position, was scored for each fly (Marley and Baines, 2011).

\section{Scoring of morphological defects}

Male and female Shu mutants were collected shortly after eclosion and scored $24 \mathrm{~h}$ later as either defective (i.e., downturned wings or indented thorax) or normal (wild-type wing posture/thorax).

\section{Lifespan assay}

Newly eclosed Shu (Shu/+) and CS (+/+) females were collected under $\mathrm{CO}_{2}$ anesthesia shortly after eclosion and kept in groups of $\sim 10$ or 20 in regular or lithiumcontaining food vials at $25^{\circ} \mathrm{C}, 60-70 \%$ humidity. Flies were transferred to new vials every $3 \mathrm{~d}$, and survivors were scored every day.

\section{Drug treatment}

Lithium chloride (LiCl; Sigma-Aldrich, St. Louis, MO) was dissolved in water to generate 1-, 0.5-, and 0.25-M stock solutions, which were added to the standard fly food in a 1:10 dilution to produce the final concentrations used in these studies. Newly eclosed flies were transferred to vials with $\mathrm{LiCl}$-containing food and aged for 1-5 d before experiments were performed. For the experiments to evaluate the effects of inhibitors for GSK-3 or IMP, larvae were raised in the standard food containing 20 $\mu \mathrm{M}$ AR-A014418 (Sigma-Aldrich) or $0.5 \mathrm{~mm}$ L-690330 (Tocris, Bristol, UK) at $25^{\circ} \mathrm{C}$. AR-A014418 and L-690330 were initially dissolved in DMSO and water to generate 20- and 0.5-M stock solutions, respectively. The eclosed adult flies were scored for their morphological phenotype and continued to be grown on the drug-containing food for 5-6 d before being assessed for locomotor activity.

\section{Measurement of internal lithium}

Twenty virgin female flies were placed in a vial with food containing 25,50 , or $100 \mathrm{~mm} \mathrm{LiCl}$ for $5 \mathrm{~d}$ and were homogenized in $350 \mu$ l of $1 \times$ PBS (pH 7.4). The homogenate was centrifuged at $15,000 \mathrm{rpm}$ for $15 \mathrm{~min}$ and filtered through a Nanosep spin filter cartridge $(0.2-\mu \mathrm{m}$ pore size; Pal Corp., East Hills, NY). The supernatant was subjected to lithium analysis performed by the University of lowa Hospitals and Clinics Pathology Laboratory using spectrophotometry with the Infinity lithium single liquid stable reagent (Thermo Fisher Scientific, Waltham, MA).

\section{Molecular biology}

\section{Genomic DNA isolation and sequencing}

Genomic DNA was isolated from heads of wild-type or Shu males and used as a template for PCR amplifications. Based on FlyBase sequence information, primer sets were designed to amplify para exons. PCR amplifications were carried out using proofreading DNA polymerases as described in our previous study (Kasuya et al., 2009a). The PCR products were cloned into the pCR2.1 TA clon- ing vector (Invitrogen, Grand Island, NY) for sequencing analyses. Resulting exon sequences were compared between those of wild-type and Shu mutant flies to identify mutations. At least five clones from one PCR amplification were sequenced to confirm that the identified mutation was not the result of a PCR error.

\section{Construction of pUAS-para plasmids}

Total RNA was extracted from heads of wild-type or Shu males and used to generate complementary DNA (cDNA) with the Superscript III reverse transcriptase kit (Invitrogen). The cDNA was used as a template to amplify a 461-bp Blp1 fragment with the primers $\mathrm{Na}_{v} 1.1 \mathrm{Blpl}$, forward 5'-ATT TCC GAT CTT AGC CGG TG-3' and reverse 5' -ACA GAT ACG CGT TAC CTA CAT GAT C-3', respectively. The amplified fragment completely covered para exons 24-26 and partially covered exons 23 and 27. The Shu mutation resides in exon 24 . The PCR products from both wild-type and Shu mutant cDNA were then purified, digested with Blp1, and cloned into pGH19$\mathrm{Na}_{\mathrm{v}} 1.1$ plasmid kindly provided by Mark Tanouye (Parker et al., 2011), at Blp1 sites to replace the Blp1 fragment. $\mathrm{Na}_{\mathrm{v}} 1.1$ cDNAs with or without the Shu mutation were excised from the pGH19 vector using Kpnl and Xbal and subcloned into the pUAST vector using the same restriction enzymes. The entire para cDNA was sequenced to confirm that no nonsynonymous nucleotide substitutions other than the Shu mutation (see Results) were present compared with $\mathrm{Na}_{\mathrm{v}} 1.1$.

\section{Adult flight muscle electrophysiology}

As described previously (Engel and Wu, 1992; Lee and $\mathrm{Wu}, 2002$; lyengar and $\mathrm{Wu}, 2014)$, adult flies were briefly anesthetized on ice, tethered to a tungsten wire using cyanoacrylate glue, and allowed to rest for $30 \mathrm{~min}$. For recordings of flight-muscle activity, an electrolytically sharpened tungsten electrode was inserted into the top dorsal longitudinal muscle (DLMa), and a similar reference electrode was placed into the abdomen. DLM action potentials $\left(\mathrm{Ca}^{2+}\right.$ spikes) were amplified by an $\mathrm{AC}$ amplifier (bandwidth $10 \mathrm{~Hz}$ to $20 \mathrm{kHz}$, Model 1800, AM Systems, Sequim, WA) and digitized at $20 \mathrm{kHz}$ by a USB 6210 DAQ card (National Instruments, Austin, TX) controlled by a custom script written in LabVIEW 8.6 (National Instruments). We examined the properties of the giant-fiber (GF) pathway as well as seizure discharges in DLMs triggered by electroconvulsive stimulation (ECS) across the brain. In addition, nonflight spontaneous DLM activity was monitored.

The two parameters of the GF pathway characterized were the DLM response latency and following frequency. The GF pathway was stimulated by $0.1-\mathrm{ms}$ pulses at about $30 \mathrm{~V}$ generated by an isolated pulse stimulator (AM Systems Model 2100) delivered via tungsten electrodes inserted into each eye. In this study, DLM response latency was determined to be the time between GF stimulation and the time at which DLM spike reached its halfmaximum height. The ability of the GF pathway to follow high-frequency stimulation was assessed by delivering a series of 10-pulse trains at increasing frequencies from 20 to $200 \mathrm{~Hz}$, at $20-\mathrm{Hz}$ increments, with $5 \mathrm{~s}$ between stimulus 
trains. The number of GF responses successfully recruited in each stimulus train was recorded, and the interpolated stimulus frequency at which five responses could be recruited indicated the $50 \%$ success following frequency $\left(\mathrm{FF}_{50}\right)$.

The ECS protocol used to trigger DLM seizure discharges (Lee and Wu, 2002; lyengar and Wu, 2014) consisted of a 2-s train of high-frequency pulses $(0.1 \mathrm{~ms}, 200$ $\mathrm{Hz}$ ), with voltages ranging from 30 to $80 \mathrm{~V}$ as specified. To avoid refractoriness, flies were allowed to rest at least 10 min between ECS trains. ECS typically evokes a seizure discharge repertoire characteristic to different genotypes, including wild-type (Lee and Wu, 2002, 2006). In this study, we confined our analyses to the period immediately after ECS, which consists of a high-frequency burst of DLM spikes discharge corresponding with behavioral spasms (Pavlidis and Tanouye, 1995; Lee and Wu, 2002; lyengar and Wu, 2014). In wild-type flies, this initial seizure discharge usually lasted $\sim 1 \mathrm{~s}$, whereas it often lasts more than $10 \mathrm{~s}$ in Shu (Fig. 2D). Thus, our spike counts per trial included a period of $8 \mathrm{~s}$, even though in the wild-type, the seizure discharge seldom persisted more than $1 \mathrm{~s}$. We considered a burst activity beyond five spikes time-locked to ECS to indicate above-threshold activity. This criterion effectively differentiates near-threshold seizure discharges from sporadic background spontaneous firing often observed in a tethered fly (Engel and Wu, 1992; Lee and $\mathrm{Wu}, 2006)$.

\section{Larval neuromuscular junction electrophysiology}

Preparation of postfeeding wandering third instar larvae and recordings of excitatory junctional potentials (EJPs) and nerve action potentials were carried out as described previously (Ueda and Wu, 2006; Lee et al., 2008). Briefly, dissections were performed in $\mathrm{Ca}^{2+}$-free $\mathrm{HL} 3$ saline (in $\mathrm{mm}$ ): $70 \mathrm{NaCl}, 5 \mathrm{KCl}, 20 \mathrm{MgCl}_{2}, 10 \mathrm{NaHCO}_{3}, 5$ trehalose, 115 sucrose, and 5 HEPES, at pH 7.2 (Stewart et al., 1994), and EJPs and nerve action potentials were recorded in the modified HL3.1 saline (with $\mathrm{MgCl}_{2}$ reduced to $4 \mathrm{~mm}$ and $0.2 \mathrm{~mm} \mathrm{CaCl}_{2}$ added; Feng et al., 2004). The segmental nerve was severed from the ventral ganglion, and stimuli were delivered through the cut end with a suction electrode (10- $\mu \mathrm{m}$ internal diameter). The stimulation voltage was adjusted to twice the threshold to ensure action potential initiation. For EJP recordings, intracellular glass microelectrodes were filled with $3 \mathrm{~m} \mathrm{KCl}$ and had a resistance of $\sim 60 \mathrm{M} \Omega$. Signals were recorded with a DC pre-amplifier (model M701 microprobe system, World Precision Instruments, Sarasota, FL). Compound action potentials were recorded from the segmental nerve en passant with a suction pipette (Wu et al., 1978). Data were digitized and analyzed on a PC.

\section{Microarray analysis}

Microarray analysis was performed as previously described (Kasuya et al., 2009b). One-d-old female flies were kept in a vial containing the regular cornmeal-based food with or without $50 \mathrm{~mm} \mathrm{LiCl}$ for $24 \mathrm{~h}$. Their heads were cut on a dry ice block and stored at $-80^{\circ} \mathrm{C}$ until use. Total RNA was extracted from $\sim 75-100$ fly heads using TRIzol Reagent (Invitrogen) followed by an RNeasy (Qiagen, Va- lencia, CA) cleanup step and DNase I digestion. The RNA was resuspended in diethylpyrocarbonate-treated water and subjected to microarray analysis. Three independent RNA samples were prepared and analyzed for each treatment group. Microarray experiments were carried out at the Translational Genomics Research Institute (Phoenix, AZ) using Affymetrix Drosophila Genome 2.0 Arrays (Affymetrix, Santa Clara, CA). Each chip is composed of 18,800 probe sets representing more than 18,500 transcripts. Image data were quantified by using the Genechip-operating software Affymetrix GCOS v1.4. Gene expression data were analyzed using GeneSpring software. We focused on genes that were detected in all three replicates for at least one of the two conditions in comparison. The comparisons were made between signals for CS and Shu/+ with or without lithium treatment using Welch's $t$-test (Kasuya et al., 2009b). Comparisons were also made using one-way ANOVA, and Bonferroni multiple-comparison corrections were applied to obtain the false discovery rate. Genes were annotated and biological processes were analyzed using Database for Annotation, Visualization, and Integrated Discovery (DAVID) v6.7 (https://david.ncifcrf.gov/; Huang et al., 2009).

\section{Reverse-transcription PCR analysis}

For semiquantitative and real-time reverse-transcription (RT)-PCR, RNA was extracted using the methods described above, and single-strand cDNA libraries were synthesized with DNase l-treated RNA using Superscript III reverse transcriptase kit (Invitrogen) or, in the real-time experiments, iScript cDNA Synthesis Kit (Bio-Rad Laboratories, Hercules, CA). For semiquantitative RT-PCR, conditions for PCR reactions were optimized for each gene such that the endpoint of each $\mathrm{PCR}$ reaction was in the linear range of amplifications. Transcript-level quantification analyses were measured by analyzing pixel intensity of the bands using Image $\mathrm{J}(\mathrm{NIH})$. For quantitative real-time RT-PCR, cDNA samples were analyzed using a CFX96 Real-Time System (Bio-Rad Laboratories), with each $20 \mu \mathrm{l}$ reaction containing $10 \mu \mathrm{l}$ of SsoAdvanced Universal SYBR Green Mastermix (Bio-Rad Laboratories), 2 ng of cDNA, and RT primers designed using PrimerQuest (Integrated DNA Technologies, Coralville, IA) at a final concentration of $300 \mathrm{nM}$. Before RT-PCR experiments, primer efficiencies were determined from dilution curves (1:10) using the formula: $E=10^{-1} /$ slope (Pfaffl, 2001). Fold-change was determined using the $\Delta \Delta \mathrm{Ct}$ method (Livak and Schmittgen, 2001). Primers used in the RT-PCR experiments are listed in Table 7.

\section{Statistical analysis}

For behavioral experiments, statistical comparisons between two groups were performed using a two-tailed Student's $t$-test assuming unequal variance or, in the case of non-normally distributed data, the Mann-Whitney $U$-test was used. Statistical significance between multiple groups displaying a normal distribution was determined using one-way ANOVA with Bonferroni-corrected $t$-test comparisons between control and treatment groups post hoc. For those data exhibiting nonnormal distributions, Kruskal-Wallis one-way ANOVA on ranks was performed. 
Comparisons between groups or groups versus a control were calculated using Dunn's method post hoc. Data not conforming to a normal distribution are represented as box plots in most cases. The log-rank Kaplan-Meier survival test was applied to analyze survival time. Statistical analyses were performed using SigmaStat for Windows Version 3.11 (Systat Software, Point Richmond, CA). Differences between mean or median values were considered significant at $p<0.05$. The microarray gene expression data were analyzed using GeneSpring software (Agilent Technologies, Santa Clara, CA). The comparisons were made between genotypes (i.e., $+/+$ or $\mathrm{Shu} /+$ ) or drug treatments (i.e., with or without LiCl). Lists were filtered for the genes that were present in all three independent samples of at least one of the two genotypes.

\section{Results}

\section{Outcrossed Shu mutants exhibit morphological and behavioral abnormalities}

In the original study by Williamson (1982), phenotypes of Shu mutants were examined using Shu/FM6 female flies, where FM6 is a balancer $\mathrm{X}$ chromosome with multiple inversions and marker mutations. It was therefore possible that genetic aberrations in the FM6 balancer chromosome contributed to the previously reported dominant phenotypes of Shu. To rule out this possibility, the following phenotypic analyses were carried out with the progeny of crosses between control males and Shu females with the $\mathrm{X}$ chromosome balancer (i.e., Shu/+ and Shu/Y). To minimize potential effects of unidentified genetic variations in the original Shu genome, we used a Shu mutant stock that had been backcrossed to $C S$ for at least 26 generations. Outcrossed Shu males (Shu/Y) survived for only a few days after eclosion and were too sluggish to perform behavioral tasks. Under our standard rearing conditions, Shu males displayed severe defects in courtship behavior and rarely copulated. Consequently, homozygous adult Shu females (Shu/Shu) were not normally found in Shu mutant stocks. Our reassessment revealed morphological and behavioral defects in Shu mutants, some of which had been reported for the original Shu/FM6 stock in Williamson (1982); others are described for the first time in this study.

Shu males (Shu/Y) and heterozygous females (Shu/t, hereafter referred to as Shu or Shu females unless otherwise stated) were found to exhibit an abnormal wing posture (downturned wings) and a cuticular defect on the back (indented thorax), neither of which was observed in wild-type flies (Fig. 1A). These morphological phenotypes manifested shortly after eclosion and at high penetrance in both sexes. In Shu males, $88 \%$ and $69 \%$ exhibited downturned wings and an indented thorax, respectively ( $n$ $=272$ ), whereas in Shu females $73 \%$ and $65 \%$ displayed the defects $(n=683)$. Similar morphological abnormalities have been reported in Shaker $(S h)$ mutants harboring a second genetic lesion in either ether-a-go-go (eag; Ganetzky and Wu, 1983; Engel and Wu, 1992) or receptor oscillation A (rosA; Wu and Wong, 1977) also known as inebriated (ine; Stern and Ganetzky, 1992), or when com- bined with a para duplication (Stern et al., 1990). Sh and eag encode the $\alpha$-subunit of voltage-gated potassium channels $\mathrm{K}_{\mathrm{v}} 1$ (Kamb et al., 1987; Papazian et al., 1987; Pongs et al., 1988) and $K_{v} 10$ (Warmke et al., 1991), respectively, whereas rosA/ine encodes the neurotransmitter/osmolyte transporter (Burg et al., 1996; Soehnge et al., 1996). Double mutants for the gene quiver (qvr; Humphreys et al., 1996) and either eag or Hyperkinetic (Hk; Kaplan and Trout, 1969) show similar defects in wing posture and thoracic morphology (Wang et al., 2000). Hk encodes the auxiliary $\beta$-subunit for the Sh $\mathrm{K}_{\mathrm{v}} 1$ channel (Chouinard et al., 1995), and mutations of $H k$ and qvr modify the Sh K current (Wang and Wu, 1996; Yao and Wu, 1999; Wang and Wu, 2010). These morphological abnormalities are thought to be caused by an increase in neuronal excitability that leads to hypercontraction of the relevant thoracic muscles (Engel and Wu, 1992; Huang and Stern, 2002).

As reported by Williamson (1982), Shu mutants displayed sporadic, spontaneous tremors or "shuddering." This behavioral abnormality was nearly absent during the first $8 \mathrm{~h}$ after eclosion. However, $24 \mathrm{~h}$ later, the frequency of severe shuddering episodes (resulting in the fly being thrown onto its back) increased significantly and remained at this level throughout the 10-d period of observation (Fig. 1B). In contrast, wild-type flies displayed these types of episodes only rarely when first introduced into the observation chamber. We also performed a reactive climbing assay using a countercurrent apparatus (Benzer, 1967 ) to assess the general activity and motor coordination of Shu mutants. Defects in this behavior were clearly evident in Shu mutants soon after eclosion and further deteriorated in an age-dependent manner (Fig. 1C).

In an effort to better quantify the behavioral abnormalities of Shu mutants (e.g., jerking, twitching, and uncoordinated locomotion), we also analyzed their movements using an automated system originally developed for Drosophila sleep analysis (Gilestro and Cirelli, 2009). When placed in a circular chamber, wild-type flies spent most of their time along the periphery (Besson and Martin, 2005), resulting in tracking patterns resembling a circle. In contrast, the uncoordinated movements and spontaneous jerking of Shu mutants led to their increased presence in the center part of the chambers, as represented by a typical tracking trace (Fig. 1D). During the 10-min recording period, Shu mutants spent a significantly longer time in the center than wild-type flies. Typical median percentages of time spent in the center of the chamber were $4.8 \%$ for wild-type flies $(n=63)$ and $39.5 \%(n=53)$ for Shu mutants $(P<0.001)$.

\section{Shu mutants display an ether-induced shaking phenotype and reduced lifespan}

Shu mutants were reported to exhibit leg-shaking behavior under ether anesthesia (Williamson, 1982). This behavioral phenotype has previously been observed in several other mutants with enhanced neuronal excitability, such as the aforementioned Sh, eag, Hk, and qvr mutant strains (Kaplan and Trout, 1969; Wang et al., 2000). To analyze this behavioral phenotype in a semi-quantitative 
A

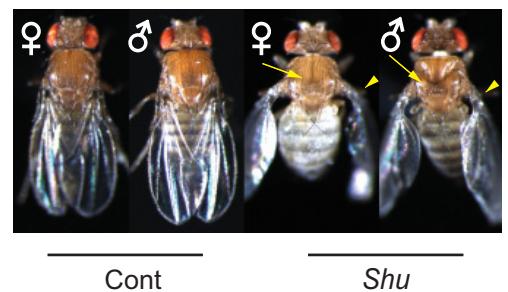

D

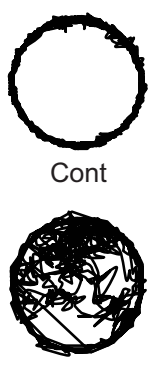

Shult
E

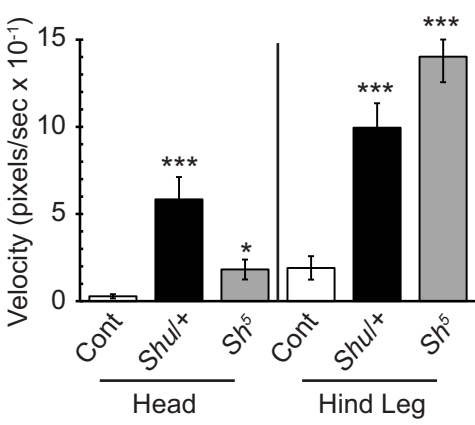

B

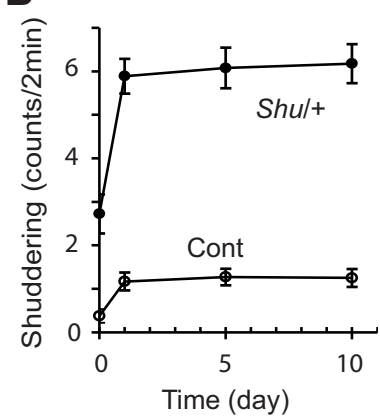

C

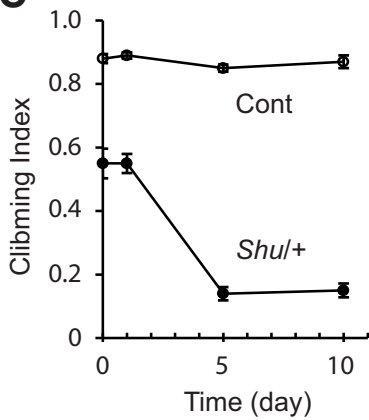

$F$

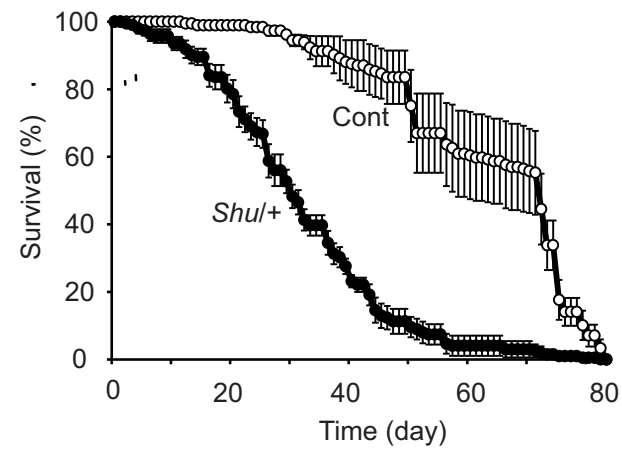

Figure 1. Shu mutants exhibit abnormalities in morphology, behavior, and lifespan. $\boldsymbol{A}$, Shu males (Shu/Y) and females (Shu/+) often display downturned wings (arrow head) and an indented thorax (arrow), which are not observed in wild-type flies (Cont). B, 0- to 10-d-old Shu (Shu/+) and wild-type (Cont) female flies were scored for the number of times in 2 min that a strong convulsive episode resulted in the fly being thrown onto its back. Wings of the mutant and control flies were removed shortly after eclosion to eliminate possible effects of downturned wings of Shu mutants on shuddering behavior. Data are mean \pm SEM. $n \geq 30$. $\boldsymbol{C}$, The general activity and motor coordination of Shu mutants were assessed by a reactive climbing assay using a countercurrent apparatus. 0- to 10-d-old wild-type (Cont) and Shu (Shu/+) females were used. To ensure that the climbing defect was not simply due to the downturned wing phenotypes of the fly, wings of the mutant and control flies were removed shortly after eclosion. Data are mean \pm SEM for 10 groups of 20 flies. D, Representative locomotion traces of wild-type (Cont) and Shu (Shu/+) females in a circular chamber. Compared with wild-type flies, which travel mostly along the edge of the chamber, Shu mutants spent significantly longer times in the center of the chamber. $\boldsymbol{E}$, Head and hind leg movements under ether anesthesia were video recorded at 15 frames/s, and their velocities (pixels/frame) in wild-type (Cont), Shu (Shu/+), and $S h^{5}$ females are shown as mean \pm SEM. Data for head and leg movements were analyzed using Kruskal-Wallis one-way ANOVA on ranks followed by Dunn's test, and one-way ANOVA followed by Bonferroni test, respectively. The statistical significance of differences between wild-type (Cont) and each genotype $\left(S h u /+\right.$ or $\left.S h^{5}\right)$ is shown. $* p<$ 0.05 ; ***p $<0.001$. $n=11$. F, Survival of CS (Cont) and Shu (Shu/+) females under standard conditions at $25^{\circ} \mathrm{C}, 60-70 \%$ humidity. Flies were kept in groups of $\sim 20$. Data are presented as the daily average percentage of surviving flies in each vial with SEM. $n=$ 180 and 176 for CS and Shu, respectively. The median survival times were 72 and $30 \mathrm{~d}$ for wild-type and Shu. Two survival curves showed a statistically significant difference ( $p<0.001$, log-rank Kaplan-Meier survival analysis).

manner, we recorded ether-induced movements of the head and hind leg using a video-tracking system (see Materials and Methods). Shu mutants vigorously moved the head as well as the legs under ether anesthesia, resulting in a drastic increase in the velocities of their movements compared with wild-type flies (Fig. 1D). The ether-induced shaking phenotype of Shu was similar to, but distinct from, that of $S h^{5}$, a neomorphic mutant allele of Sh (Salkoff and Wyman, 1983; Haugland and Wu, 1990), in that Shu had a tendency to waggle the head more extensively than Sh (Fig. 1E), and that the leg movements of Shu were sporadic, whereas those of Sh were rather continuous. Moreover, legs severed from etheranesthetized Sh continued to shake (Ganetzky and Wu, 1985) whereas those severed from Shu did not, suggesting that Shu's ether-induced leg shaking phenotype likely has a central origin.
Shortened lifespan is a common feature of Drosophila mutants that display ether-induced leg-shaking, such as Sh, Hk, and qvr (Trout and Kaplan, 1970; Koh et al., 2008; Bushey et al., 2010). Similarly, the median survival time of Shu mutants was significantly reduced (30 d, $n=176$ ) compared to that of wild-type flies (72 d, $n=180 ; p<$ 0.001 , Fig. 1F).

\section{DLMs of Shu mutants exhibit drastically enhanced spontaneous activity and ECS seizure discharges}

The behavioral and morphological phenotypes of Shu mutants suggest that the excitability of their motor circuits is enhanced. The dorsal longitudinal muscles are particularly amenable to examination of changes in motor circuit function, because they serve as outputs of the motor neurons that integrate inputs, including those from the flight pattern generator (Harcombe and Wyman, 1977), 

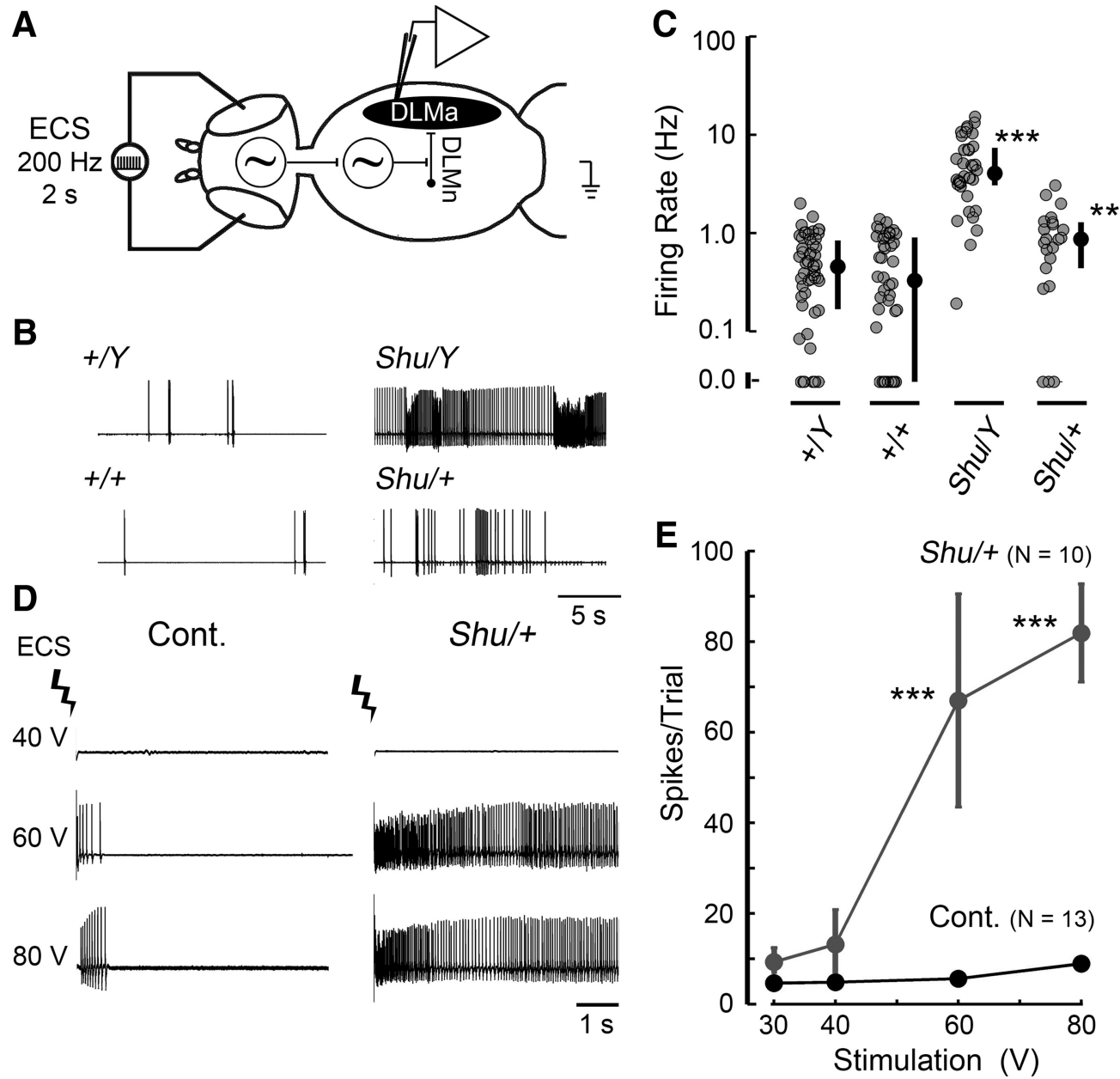

Figure 2. Shu mutants display hyperexcitable seizure-like discharges in the electrical output of an identified motor neuron. $\boldsymbol{A}$, The dorsal longitudinal motor neuron (DLMn) receives input from a number of pattern generators, and its activity may be monitored via spiking activity in the dorsal longitudinal muscle (DLM). B, Example traces of spontaneous activity in Shu males (Shu/Y) and females (Shu/+; right) compared with wild-type control individuals (left). C, Scatterplot of spontaneous firing rates in control $(+/ Y,+/+)$ and Shu (Shu/Y, Shu/+) populations. Each gray circle represents a 1-min recording of activity, black circles (right) represent the median, and vertical bars represent the 25th-75th percentile interval ( $n>10$ individuals for each group). **p $<0.01 ; * * * p<0.001$, Kruskal-Wallis ANOVA, rank-sum post hoc test. $\boldsymbol{D}$, DLM firing, monitored as readout of stereotypic seizure-like discharges triggered by high-frequency, high-voltage electroconvulsive stimulation across the brain (ECS, see Materials and Methods). Sample ECStriggered discharges in control (Cont) and Shu/t individuals are displayed. $\boldsymbol{E}$, Plot of ECS voltage and number of spikes per discharge, a measure of seizure intensity. Shu/+ individuals display significantly more intense seizure discharges at 60 and $80 \mathrm{~V}$ compared with control (Cont) flies. $* * * p<0.001$, Kruskal-Wallis ANOVA, rank-sum post hoc test.

and the GF circuit mediating the jump-and-flight escape reflex (Tanouye and Wyman, 1980; Fig. 2A). DLMs' large size and isometric contraction enable prolonged monitoring of their action potentials $\left(\mathrm{Ca}^{2+}\right.$ spikes). Importantly, this system has revealed alterations in basic physiological properties caused by a number of hypo- and hyperexcitable mutations (Siddiqi and Benzer, 1976; Elkins et al., 1986; Engel and Wu, 1992, 1998; lyengar and Wu, 2014).

Increased spontaneous nonflight DLM activity is a basic phenotype associated with hyperexcitable mutants, including the double potassium channel mutant, eag Sh (Engel and Wu, 1992). Figure 2 illustrates this spontaneous activity in Shu mutant DLMs. We found that heterozygous $S h u$ females displayed a significantly increased spike frequency compared with wild-type females $(0.99 \pm$ $0.24 \mathrm{~Hz}$ vs. $0.50 \pm 0.10 \mathrm{~Hz}, p<0.01$; Fig. $2 B, C)$. In hemizygous Shu males, this phenotype was much more striking compared with wild-type males $(5.56 \pm 0.93 \mathrm{~Hz}$ vs. $0.53 \pm 0.08 \mathrm{~Hz}, p<0.001$ ) and even greater than that previously observed in eag Sh double mutants $(\sim 3.5 \mathrm{~Hz}$; Engel and $\mathrm{Wu}, 1992)$. In contrast to these findings in spontaneous activities, analysis of the GF pathway-mediated responses to electrical stimulation across the brain revealed relatively mild effects of the Shu mutation. We examined both male and female Shu individuals for DLM spike initiation latency and the interpolated stimulus frequency at which $50 \%$ DLM responses failed $\left(\mathrm{FF}_{50}\right)$. We found only a slightly retarded DLM spike latency in Shu males and a modest increase in $\mathrm{FF}_{50}$ in $\mathrm{Shu}$ females compared with wild-type flies (Table 1).

The same recording configuration was used to examine the ECS-triggered stereotypic seizure-like discharge pat- 
Table 1. Electrophysiological properties of the GF circuit in wild-type flies and Shu mutants.

\begin{tabular}{lllll}
\hline Property & $+/+$ & $S h u /+$ & $+/ Y$ & Shu/Y \\
Latency, ms & $1.67 \pm 0.04(16)$ & $1.72 \pm 0.05(9)$ & $1.52 \pm 0.04(21)$ & $1.98 \pm 0.13 *(7)$ \\
$\mathrm{FF}_{50}, \mathrm{~Hz}$ & $168.0 \pm 3.56(13)$ & $181.8 \pm 3.90 *(14)$ & $187.4 \pm 2.63(24)$ & $183.7 \pm 3.23(7)$
\end{tabular}

$* p<0.05$; Student's $t$-test compared with wild-type counterparts. Sample numbers are indicated in parentheses.

tern. High-intensity, high-frequency ECS (up to $80 \mathrm{~V}, 200$ $\mathrm{Hz}$ ) across the brain evokes seizure activities characteristic of wild-type and a variety of mutant flies (Pavlidis and Tanouye, 1995; Lee and Wu, 2002, 2006; Ueda et al., 2008; Parker et al., 2011; Ehaideb et al., 2014). We quantified the spike patterns immediately after the ECS (initial discharge; Lee and $\mathrm{Wu}, 2002$ ) and found that in Shu females' ECS-triggered discharges were far more intense than those of wild-type females in both number of spikes per discharge (Fig. 2D, E) and duration of spike discharges. This duration was consistently $>5 \mathrm{~s}$ in Shu females (8 of 10 flies), which was rarely observed in wild-type flies. However, the ECS intensity threshold did not differ significantly between Shu and wild-type females ( $60 \mathrm{~V}$; see Materials and Methods for details).

\section{Shu maps to the Drosophila voltage-gated sodium channel gene paralytic}

The Shu mutation was previously mapped to the $\mathrm{X}$ chromosome, at the genetic map position 55.1 with respect to the vermilion and forked loci (Williamson, 1982), leaving us with a rough estimate of where the lesion might be located. We undertook a recombination-based mapping approach using molecularly defined P-element insertions to narrow down the chromosomal position of the Shu mutation (Zhai et al., 2003). To do this we recombined an eye color marker, the white mutation $(w)$, into the Shu-carrying chromosome and scored nearly 50,000 F2 flies for the recombination events between Shu mutation and six nearby P-element insertions containing the $w^{+}$ mini gene (Table 2). Calculation of the recombination rates revealed that the P-element insertions EY05861 and EY00852, nearest the gene para (CG9907), provided the lowest recombination rates $(0.18$ and $0.22 \%$, respectively), whereas insertions more distant in either direction from cytological region 14E resulted in higher rates of recombination (Table 2). Based on the molecular distance between the defined P-element insertion sites and the recombination rates between these markers and the Shu mutation, the mutation site was estimated between the insertion sites of two particular P-elements used in our screen: P[EPgy2]CG9902 ${ }^{E Y 05861}$ and P[EPgy2]Rbp2 ${ }^{\text {EY00852 }}$. All combinations pairing one insertion distal, and one proximal, to cyto- logical region 14E resulted in an estimated Shu mutation site in the 72-kb para locus (Fig. 3A), which encodes for the Drosophila voltage-gated sodium channel (Loughney et al., 1989).

\section{Shu carries a missense mutation in the paralytic coding region}

Because our recombination mapping indicated that the Shu mutation is located within the para locus, we sequenced all 31 para coding exons using genomic DNA from extensively backcrossed (40 generations) hemizygous Shu males. Our results revealed a single nucleotide change in Shu, a G-to-A transition in para exon 24 (Fig. $3 B$ ) that results in the substitution of an isoleucine for a methionine at amino acid 1327 (based on para-PE, FlyBase). We confirmed that this mutation was also present in the genomic DNA isolated from the original Shu stock obtained from R. Williamson, but not in the wild-type strain used to isogenize the mutant stock. M1327l lies in the predicted transmembrane segment S2, within homology domain III of the sodium channel (Fig. $3 \mathrm{C}$ ). Although various splicing variants are produced from the para locus, the exon containing the Shu mutation is constitutively spliced (Olson et al., 2008; Lin et al., 2009). Therefore, this amino acid replacement must be present in all $\mathrm{Na}_{v}$ isoforms in Shu mutants. In addition, the methionine mutated in Shu represents a highly conserved residue located in the $\mathrm{Na}_{\mathrm{v}}$ channel $\alpha$ subunit proteins of evolutionarily diverse animal species (Fig. $3 D$ ), including all nine human $\mathrm{Na}_{v}$ channel $\alpha$ subunit isoforms (Yu and Catterall, 2003), strongly indicating that it is important for $\mathrm{Na}_{\mathrm{v}}$ channel function.

\section{Targeted expression of the Shu $\mathrm{Na}_{v}$ channel partially phenocopies Shu phenotypes}

To directly examine whether the identified Shu mutation in para is sufficient to cause the mutant phenotypes, we generated multiple fly lines carrying a para cDNA transgene with or without the Shu mutation (UAS-Shu and UAS-para ${ }^{+}$). When five independent UAS-Shu or UASpara $^{+}$lines were crossed to the pan-neuronal driver elavGal4, the progeny did not show obvious morphological or behavioral abnormalities resembling those of Shu mutants. However, when UAS-Shu was crossed with C164-

Table 2. Recombination rates between Shu and P-element markers.

\begin{tabular}{lllll}
\hline P-element (inserted in/near) & Total flies scored & Parental genotype & Recombinant genotype & Recombination rate \\
EY00887 (Axs) & 12,881 & 12,780 & 101 & 0.78 \\
EY0859 (CanA-14F) & 6763 & 6730 & 33 & 0.49 \\
EY05861 (CG9902) & 6723 & 6711 & 12 & 0.18 \\
EY00852 (rbp2) & 8626 & 8607 & 19 & 0.22 \\
EY01983 (CG4239) & 4923 & 4888 & 35 & 0.71 \\
EY01463 (eas) & 7866 & 7798 & 68 & 0.86
\end{tabular}


A

B
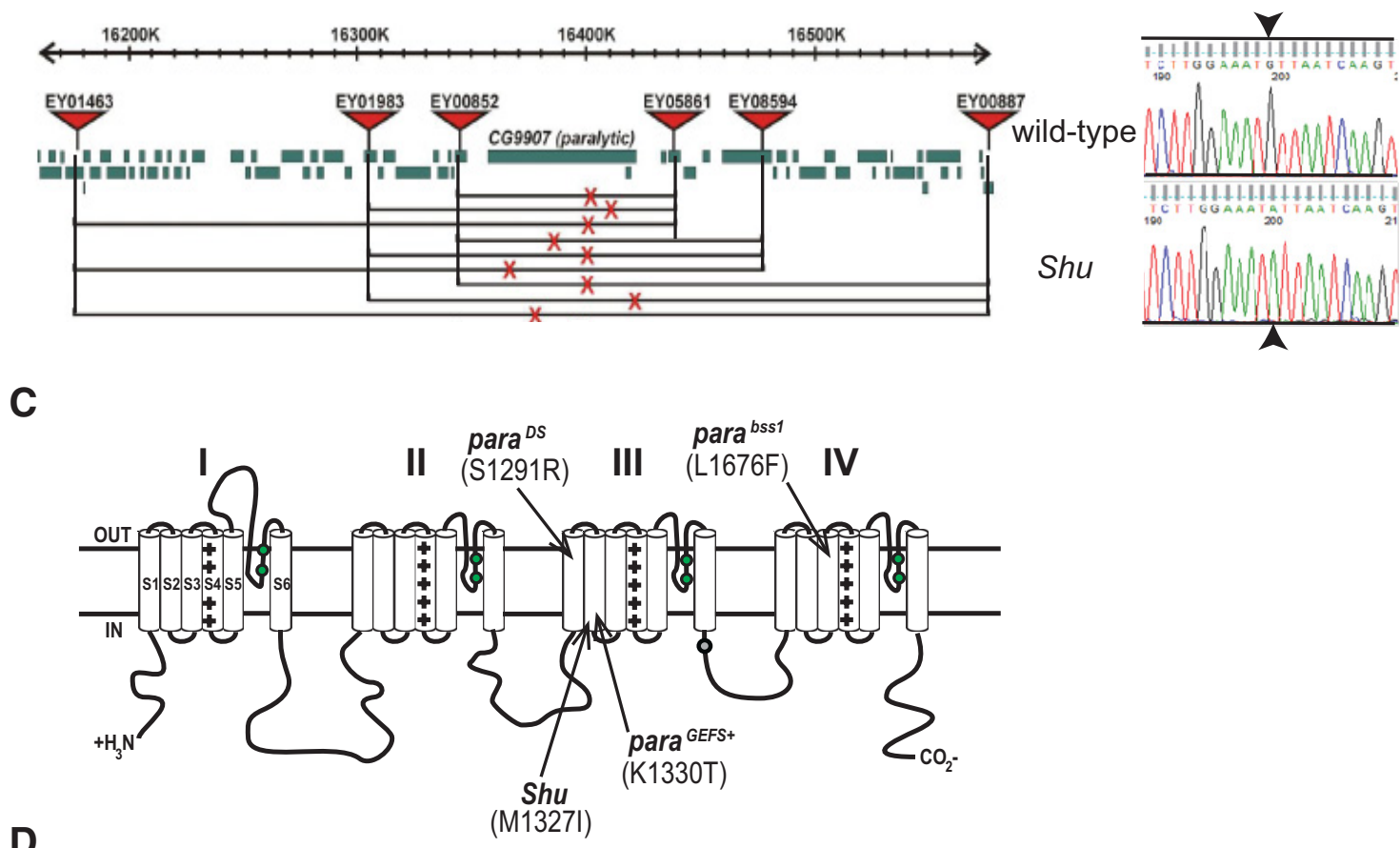

$\begin{array}{lrl}\text { Human SCN3A } & 1217 & \text { LLSSGALAFED IYIEQRKTIKTMLEYADKVFTYIFILEMLLKWVAYGFQT } \\ \text { Chimpanze SCN3A } 1228 & \text { LLSSGALAFED IYIEQRKTIKTMLEYADKVFTYIFILEMLLKWVAYGFQT } \\ \text { Dog SCN3A } & 1167 & \text { LLSSGALAFED IYIEQRKTIKTMLEYADKVFTYIFILEMLLKWVAYGFQT } \\ \text { Cow SCN3A } & 1216 & \text { LLSSGALAFED IYIEQRKTIKTMLEYADKVFTYIFILEMLLKWVAYGFQT } \\ \text { Mouse Scn3a } & 1229 & \text { LLSSGALAFED IYIEQRKTIKTMLEYADKVFTYIFILEMLLKWVAYGFQT } \\ \text { Rat Scn3a } & 1168 & \text { LLSSGALAFED IYIEQRKTIKTMLEYADKVFTYIFILEMLLKWVAYGFQT } \\ \text { Mosquito NaCh } & 1266 & \text { LLSSLALALEDVHLPQRPILQDILYYMDRIFTVIFFLEMLIKWLALGFKV } \\ \text { Drosophila para } & 1289 & \text { LMSSLALALEDVHLPQRPILQDILYMDRIFTVIFFLEMLIKWLALGFKV } \\ & & \end{array}$

Figure 3. Shu maps to the voltage-gated sodium channel gene paralytic. $\boldsymbol{A}$, Mapping positions of the Shu mutation on the $\mathrm{X}$ chromosome. Red triangles and horizontal lines represent pairs of molecularly defined P-element insertions used to estimate the Shu mutation site; red X's indicate the mutation sites deduced from the recombination rates between the corresponding P-element insertion and Shu. The estimated sites all reside within the para locus (CG9907). Boxes designate annotated genes near the para locus (based on FlyBase). B, DNA sequencing chromatogram identifying a G-to-A transition mutation (arrowheads) in the Shu genome at the position corresponding to the nucleotide 4249 in the para-RE cDNA (FlyBase). This mutation results in a methionine-to-isoleucine substitution at the amino acid position 1327. C, Schematic structural diagram of a Drosophila voltage-gated sodium channel. Arrow indicates the Shu mutation in the transmembrane segment S2 in homology domain III. The paraGEFS+ mutation K1330T, which corresponds to a SCN1A mutation K1270T causing GEFS + in humans (Sun et al., 2012), lies three codons away from that of Shu. Also shown are the para ${ }^{D S}$ mutation S1291R and the para ${ }^{b s 1}$ mutation L1676F. $\boldsymbol{D}$, Amino acid sequence alignment of $\mathrm{Na}_{\mathrm{v}}$ channels of different animal species. Note that the methionine residue, which is mutated to isoleucine in $\mathrm{Shu}$, is present in all $\mathrm{Na}_{\mathrm{v}}$ channels.

Gal4, an enhancer trap Gal4 line that drives gene expression widely in the nervous system including in motor neurons (Torroja et al., 1999; Jepson et al., 2012), a significant portion of the resulting progeny showed morphological defects similar to those seen in Shu mutants (Fig. 4A). Namely, 24 and $39 \%$ of the progeny of UAS-Shu lines 2 and 4, respectively, exhibited downturned wings. Such defects were rarely seen in any progeny of UASpara $^{+}$lines. The progeny of C164-Gal4 and UAS-Shu with the morphological abnormalities were further subjected to behavioral analysis. They were found to display sponta- neous jerking and twitching, similar to that observed in Shu mutants. In general, their locomotion was disorganized, as demonstrated by the video tracking method (Fig. $4 B$ ). The severity of the phenotype varied considerably among individuals, and only the progeny of UAS-Shu line 2 showed a statistical difference in this behavioral parameter (i.e., time spent in the center) compared with wildtype flies when the Mann-Whitney $U$-test was applied ( $p$ $<0.001)$. However, the progeny of UAS-Shu line 4 also exhibited abnormal behavior based on the observation that $14 \%$ of the tested progeny of UAS-Shu line 4 (9 of 66) 
A

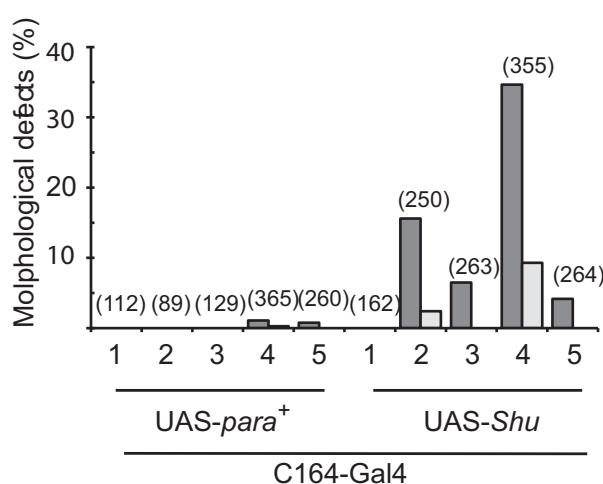

B

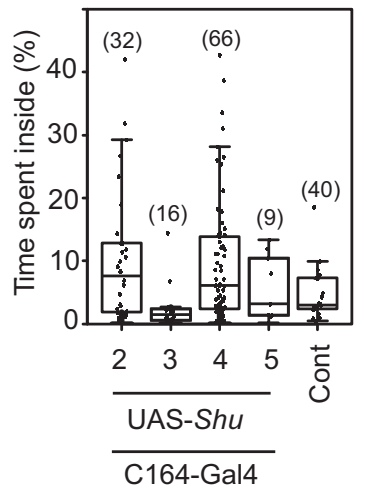

Figure 4. Targeted expression of the Shu $\mathrm{Na}_{v}$ channel partially phenocopies Shu phenotypes. A, Effects of expression of the wild-type $\left(\right.$ UAS-para $^{+}$) and Shu (UAS-Shu) $\mathrm{Na}_{v}$ channels using C164-Gal4 on morphological phenotypes. Indicated are percentages of flies with downturned wings (closed) or an indented thorax (open). The progeny of four of five independent UAS-Shu lines displayed downturned wings or an indented thorax, whereas the progeny of UAS-para ${ }^{+}$lines rarely displayed the morphological defects. $\boldsymbol{B}$, Effects of expression of the Shu $\mathrm{Na}_{v}$ channels on behavioral phenotypes. Percentages of time spent in the center of the chamber are shown for the progeny of C164-Gal4 and UAS-Shu lines. Sample numbers $(n)$ are indicated in parentheses.

spent $>20 \%$ of their time in the center, whereas no control flies ever passed this time threshold (0 of 40). These results demonstrated that targeted expression of the Shu $\mathrm{Na}_{v}$ channel can mimic, at least partially, the morphological and behavioral abnormalities observed in Shu mutants.

\section{Functional interactions between Shu and other para mutant alleles}

To infer the functional nature of the Shu mutation in para, we examined genetic interactions between Shu and other para mutant alleles, para ${ }^{t s 1}$, para ${ }^{t s 115}$, para $^{\text {bss } 1}$, and para $^{G E F S+}$. Previous studies demonstrated that para ${ }^{\text {ts } 1}$ and para ${ }^{\text {ts } 115}$ exhibit recessive, temperature-induced paralysis (Suzuki et al., 1971; Song and Tanouye, 2007), whereas parabss1 shows semidominant bang-sensitive paralysis (Parker et al., 2011). Generalized epilepsy with febrile seizures plus (GEFS+) is a common childhood- onset genetic epilepsy syndrome, often caused by a mutation in the human $\mathrm{Na}_{\mathrm{v}}$ channel gene SCN1A (Scheffer and Berkovic, 1997). para ${ }^{G E F S+}$ was generated by introducing a para mutation (K1330T) mimicking the GEFS +causing human SCN1A K1270T mutation (Fig. 3C) and was found to cause a semidominant, heat-induced seizure phenotype when exposed to $40^{\circ} \mathrm{C}$ (Sun et al., 2012).

Shu mutant females were crossed to para $^{\text {ts } 1}$, para $^{t s 115}$, para $^{\text {bss } 1}$, or para ${ }^{G E F S}+$ males, and the female progeny trans-heterozygous for Shu and another para mutant allele (i.e., Shu/para ${ }^{\text {mutant }}$ ) were subjected to phenotypic analysis. We found that the defect in wing posture was significantly suppressed in Shu females trans-heterozygous for either parats1 or parats115 (Fig. 5A). Consistently, Shu/parats1 and Shu/parats115 flies showed improved behavioral phenotypes, spending considerably less time in the center of the chamber than Shu females $(p$ $<0.001$; Fig. 5B). Because a previous report demon-
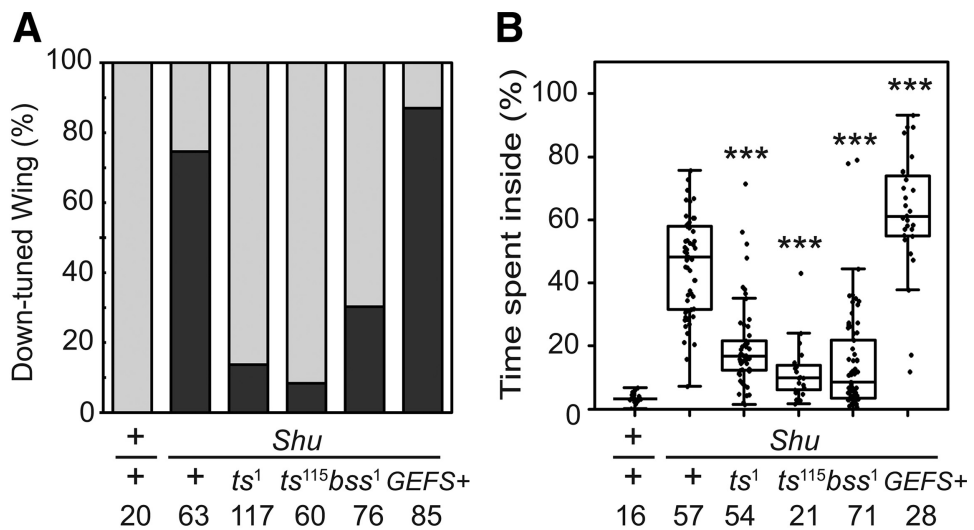

Figure 5. Functional interactions among Shu and other mutant alleles of para. $\boldsymbol{A}$, Effects of different para mutations on Shu morphological phenotype. Indicated are percentages of wild-type $(+/+)$, Shu $(S h u /+)$, and trans-heterozygous (Shu/paramutant) females exhibiting the normal wing posture (gray) and the downturned wing phenotype (black). $\boldsymbol{B}$, Effects of different para mutations on Shu behavioral phenotype. Percentages of time spent in the center of the chamber are shown for wild-type $(+/+)$, Shu (Shu/+), and trans-heterozygous (Shu/paramutant) females. The Mann-Whitney $U$ test was used to assess the effect of each para allele on the behavioral phenotype of Shu. The statistical significance and sample numbers $(n)$ are indicated. $* * * p<0.001$. 
A

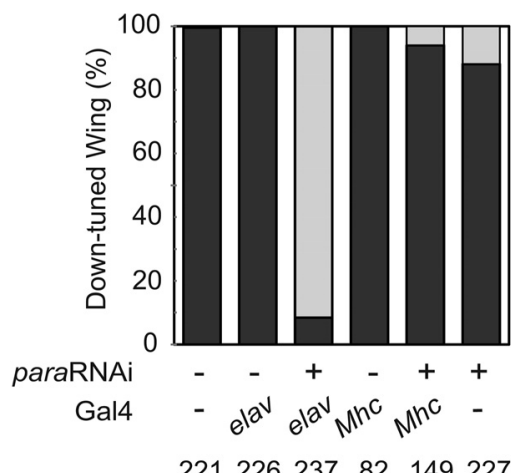

B

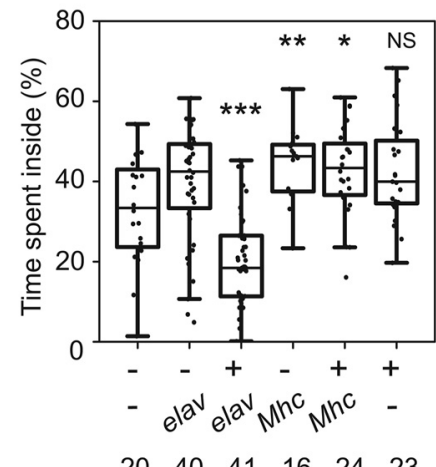

Figure 6. Neuron-specific expression of para RNAi significantly improves the Shu mutant phenotypes. $\boldsymbol{A}$, Effects of neuron-specific knockdown of para expression on Shu morphological phenotypes. Indicated are percentages of control and para RNAi-expressing flies displaying the normal wing posture (gray) and the downturned wing phenotype (black). $\boldsymbol{B}$, Effects of neuron-specific knockdown of para expression on Shu behavioral phenotypes. Percentages of time spent in the center of the chamber are shown for control and para RNAi-expressing flies. The Mann-Whitney $U$ test was used to assess the effect of each para allele on the behavioral phenotype of Shu. elav, neuron-specific elav-Gal4; Mhc, muscle-specific Mhc-Gal4. The statistical significance and sample numbers ( $n$ ) are indicated. $* p<0.05$; $* * p<0.01 ; * * * p<0.001$.

strated that para ${ }^{\text {ts1 }}$ and para ${ }^{t s 115}$ show hypomorphic function even at permissive temperature (Ganetzky, 1984), these results indicated that a general suppression of para function reduces the severity of the morphological and behavioral phenotypes of Shu mutants. On the other hand, the phenotypes of Shu mutants were not suppressed when Shu was combined with para ${ }^{\text {GEFS }}{ }^{\text {(Fig. 5A, }}$ $B)$. Rather, Shu/para ${ }^{G E F S+}$ flies displayed a more severe behavioral phenotype than Shu alone $(p<0.001$, Fig. $5 B)$. A previous study had reported that the knock-in GEFS + mutation para ${ }^{G E F S+}$ studied here reduces the activation threshold regardless of temperature (Sun et al., 2012). The worsening effect of para ${ }^{G E F S+}$ on Shu phenotypes is thus consistent with the hypomorphic alleles, parat ${ }^{t s}$ and par$a^{t s 115}$, having a suppressive effect. In this context, it was unexpected that Shu/para ${ }^{\text {bss } 1}$ displayed significantly suppressed morphological (Fig. 5A) and behavioral $(p<$ 0.001; Fig. 5B) phenotypes relative to Shu/+ flies, because, unlike parats1 or para $^{\text {ts } 115}$, para ${ }^{\text {bss1 }}$ was reported to be a gain-of-function allele (Parker et al., 2011).

\section{Neuron-specific knockdown of para leads to suppression of the Shu phenotypes}

The observation that para hypomorphic alleles partially rescued the phenotypes of Shu mutants (Fig. 5) prompted us to examine the effect of reduced para expression on the Shu phenotypes. Shu mutants were subjected to knockdown of para expression using UAS-para-RNAi lines obtained from Vienna Drosophila Resource Center (GD6131 and GD6132). Flies expressing GD6131 para$R N A i$ in neurons exhibited slightly delayed eclosion, but the adults appeared healthy. Interestingly, this genetic manipulation in Shu mutants resulted in nearly complete rescue of the downturned wing phenotype (Fig. 6A). The behavioral phenotype was drastically improved as well (Fig. 6B). Expression of para-RNAi in muscle cells using the muscle-specific driver Mhc-Gal4 did not lead to improvement of any aspects of the mutant defects examined. In support of the results with GD6131, we observed similar rescue effects when using another para-RNAi line, GD6132, to suppress para expression in Shu mutants (data not shown).

\section{Lithium reduces the severity of Shu's behavioral phenotypes}

One of the remarkable observations by Williamson (1982) was that the behavioral phenotypes of Shu/FM6 flies were significantly suppressed by feeding the mutants lithium-containing food. To examine the effect of lithium on outcrossed Shu mutants, we fed the adult flies food supplemented with different concentrations of LiCl. Consistent with the previous report (Williamson, 1982), a 5-d treatment with $100 \mathrm{~mm} \mathrm{LiCl}$ during adulthood reduced the frequency of shuddering (Fig. 7A). In addition, food containing lower concentrations of $\mathrm{LiCl}(25$ and $50 \mathrm{~mm}$ ) was also effective in suppressing shuddering behavior (Fig. $7 A)$. The reduction in shuddering in response to lithium is not due to a general suppression of motor activity, because the same treatment considerably increased coordinated motor activity of $S h u$ mutants in a reactive climbing assay (Fig. 7B). This improvement was observed in a dose-dependent manner, with higher climbing indices correlating with an increase in $\mathrm{LiCl}$ concentration $(25,50$ and $100 \mathrm{~mm}$ ) in the food. In sharp contrast to the normalizing effects of lithium on Shu mutant behavior, wild-type flies remained largely unaffected. However, after $5 \mathrm{~d}$ of receiving the highest concentration of lithium tested, wildtype flies began to display subtle signs of retarded locomotion (Fig. 7B).

Consistently, Shu mutants fed food supplemented with $100 \mathrm{~mm}$ lithium spent significantly less time in the center of the chamber compared with those maintained on standard food ( $p<0.001$; Fig. $7 C$ ). The potassium channel mutant, $S h^{5}$, also exhibited jerking and twitching, albeit less frequently and less intensely than Shu. Like Shu, $S h^{5}$ mutants spent more time in the center than wild-type flies (control vs. Shu ${ }^{5}$, no lithium, $p<0.001$ ). However, unlike 
A

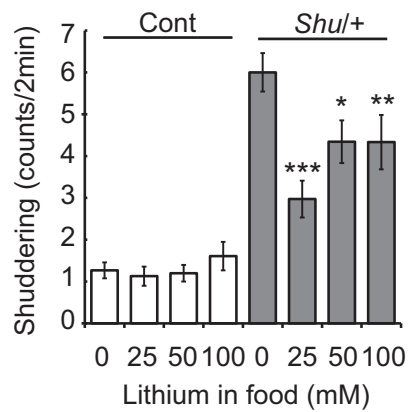

B

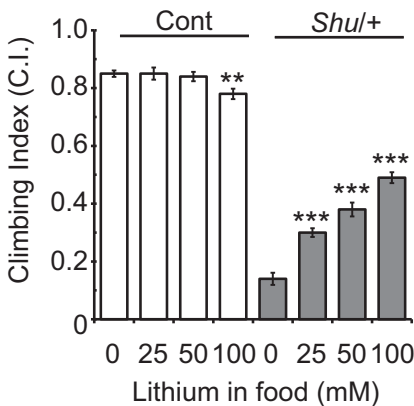

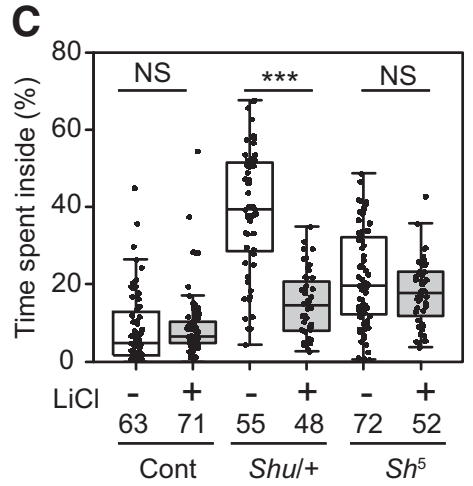

Figure 7. Lithium reduces the severity of behavioral phenotypes of Shu mutants. $\boldsymbol{A}$, Shuddering behavior in wild-type (open) and Shu females (closed) after 5-d treatment with food containing 0, 25, 50, or $100 \mathrm{~mm} \mathrm{LiCl}$. Data are mean \pm SEM. $n \geq 30$. The statistical significance of differences between the control and each lithium treatment was assessed using the Mann-Whitney $U$ test. $* p<0.05$; $* * p<0.01 ; * * * p<0.001$. B, Reactive climbing ability of wild-type (open) and Shu females (closed) after the same LiCl treatment. Data are mean \pm SEM of 10 groups of 20 flies. The statistical significance of differences between the control and each lithium treatment was assessed using the Student's t-test. $* * * p<0.001$. C, Percentages of time spent in the center of the chamber by wild-type (Cont), Shu $(S h u /+)$, and $S h^{5}$ females with or without lithium treatment. Kruskal-Wallis one-way ANOVA on ranks was performed followed by post hoc analysis using Dunn's method. Sample numbers $(n)$ and the statistical significance between lithium-treated and control flies are indicated. $* * * p<0.001$; NS, not significant $(p>0.05)$.

Shu, these same parameters in $S h^{5}$ were not significantly altered by lithium treatment (Fig. 7C).

As shown in Figure $1 F$, Shu mutants were short-lived. Although lithium had a rescue effect on Shu behavioral phenotypes (Fig. 7), it did not positively impact their longevity. Rather, Shu lifespan was decreased when adults were maintained on food containing 50 and $100 \mathrm{~mm} \mathrm{LiCl}$. Furthermore, even at the lower concentrations of lithium supplementation (i.e., 1 and $10 \mathrm{~mm}$ ), the drug failed to extend the lifespan of the mutants. The median survival times of Shu mutants in this set of experiments were 13 ( $n$ $=100), 22(n=150), 36(n=172), 30(n=147)$, and 44 $(n=139) \mathrm{d}$ for $100,50,10,1$, and $0 \mathrm{~mm} \mathrm{LiCl}$.

\section{Shu mutants accumulate higher levels of lithium}

Although lithium treatment partially rescued behavioral phenotypes of Shu mutants, it had little or even a worsening effect on the behaviors of wild-type flies (Fig. 7A-C). To determine whether there was any difference between the two genotypes with respect to physiological responses to lithium, the internal concentrations of lithium in flies fed lithium-containing food for $5 \mathrm{~d}$ were analyzed. Shu mutants were found to accumulate higher levels of lithium than wild-type flies when fed food containing either 25 or $50 \mathrm{~mm} \mathrm{LiCl}(p<0.05$; Table 3). A similar trend was observed when $100 \mathrm{~mm} \mathrm{LiCl}$ was used, although the

Table 3. Internal lithium levels in control and Shu mutants after treatment with different concentrations of $\mathrm{LiCl}$.

\begin{tabular}{llll}
\hline Fly & $25 \mathrm{~mm} \mathrm{LiCl}$ & $50 \mathrm{~mm} \mathrm{LiCl}$ & $100 \mathrm{~mm} \mathrm{LiCl}$ \\
Control & $0.176 \pm 0.011$ & $0.303 \pm 0.053$ & $0.614 \pm 0.11$ \\
Shul+ & $0.321 \pm 0.044 *$ & $0.503 \pm 0.055 *$ & $0.935 \pm 0.15$
\end{tabular}

Lithium levels in CS and Shu females after $5 \mathrm{~d}$ of treatment with 25, 50, and $100 \mathrm{~mm} \mathrm{LiCl}$. Internal lithium levels were elevated in LiCl-treated 25 or 50 $\mathrm{mm}$ ) Shu flies relative to wild-type counterparts. Data are mean \pm SEM of three independent experimental groups of 20 flies. $* p<0.05$; Student's $t$-test. difference between the genotypes was not statistically significant. Our wild-type data were comparable to internal lithium concentrations determined in previous studies under similar conditions (Padiath et al., 2004; Dokucu et al., 2005).

\section{Different para mutants are affected by lithium in an allele-specific manner}

As mentioned above, the para mutation in a Drosophila GEFS + model (para ${ }^{G E F S}{ }^{+}$) is located near the site of the Shu mutation (Fig. 3C; K1330T vs. M1327l), presenting the possibility that $S h u$ might also exhibit heat-induced seizures. Therefore, we tested Shu mutants and found that they respond to increased temperature in a manner similar to that previously observed in GEFS + flies-albeit in a much more severe manner. Seizure-like behaviors were induced in almost all Shu mutants within $30 \mathrm{~s}$ of exposure to $40^{\circ} \mathrm{C}$, whereas during the same time frame, only a few para ${ }^{G E F S+}$ heterozygotes and $<50 \%$ of para $^{\text {GEFS }+}$ homozygotes showed the phenotype (Fig. $8 A$ ). Unlike GEFS + flies, Shu mutants exhibited seizures even at $37^{\circ} \mathrm{C}$ (Fig. 8B). As was the case for other behavioral abnormalities of Shu mutants, the heat-induced phenotype was alleviated when the flies were fed food containing $100 \mathrm{~mm}$ lithium (Fig. 8B). Furthermore, lithium had a comparable rescue effect on para ${ }^{\text {GEFS }+}$ homozygotes, significantly reducing the severity of their heat-induced seizure phenotype (Fig. 8C).

Because lithium feeding suppressed the phenotype of para $^{G E F S+}$, we wondered whether phenotypic severity of other para mutants was similarly improved by lithium. para $^{D S}$ is a fly model of human epilepsy generated by Schutte et al. (2014). This knock-in allele carries the mutation in para (S1291R) that corresponds to the human SCN1A mutation (S1231R) causing a severe seizure disorder termed Dravet syndrome (DS). Drosophila para ${ }^{D S}$ mutants exhibit heat-induced seizures with onset temper- 
A

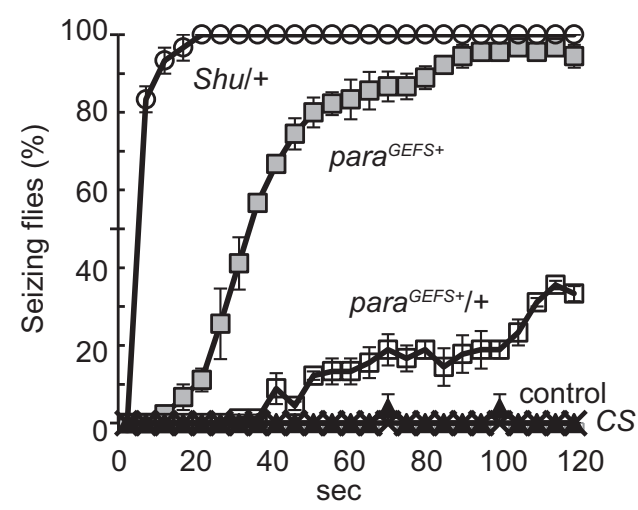

C

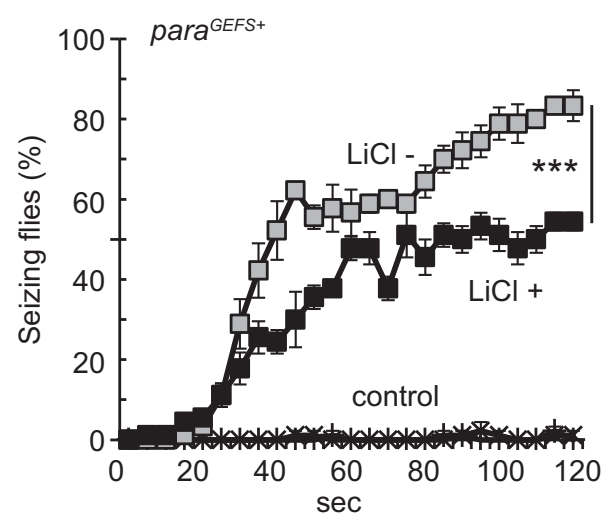

E

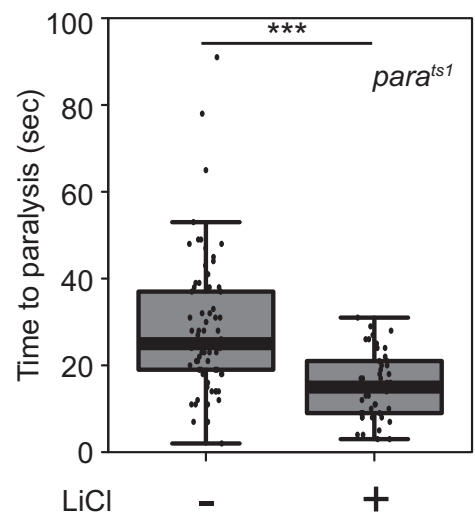

B

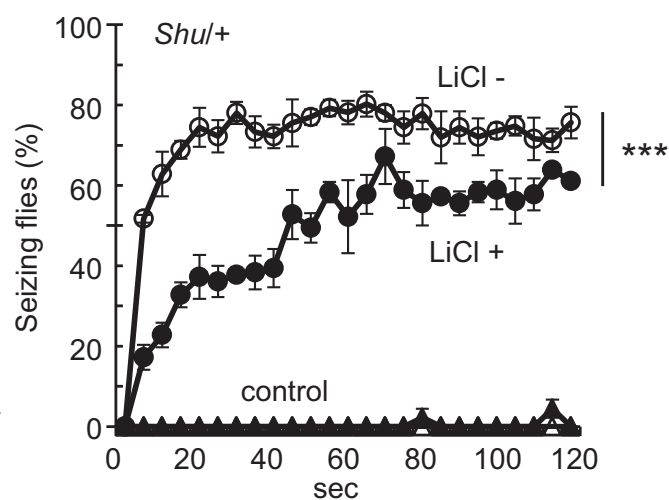

D

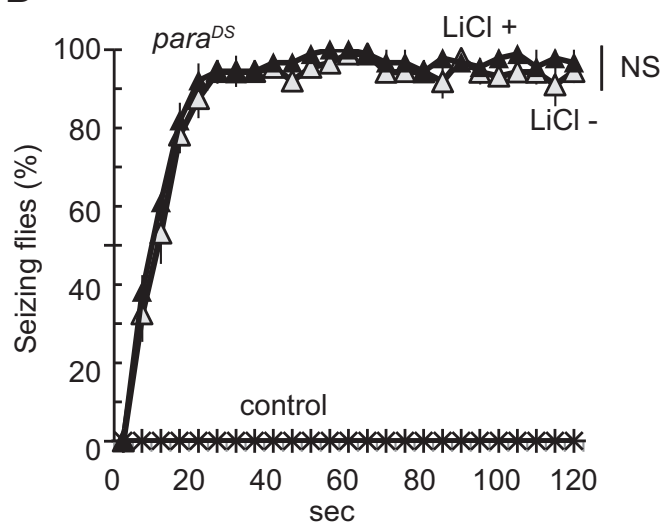

F

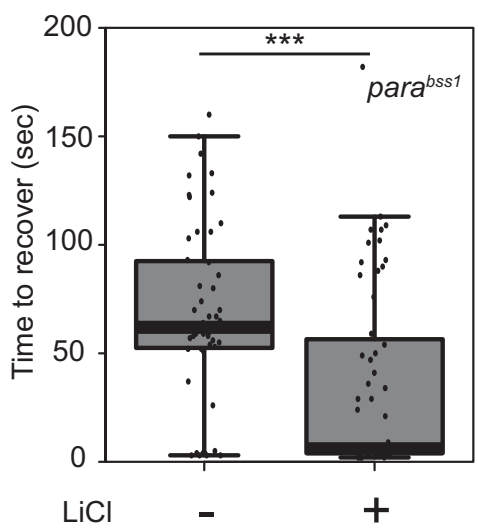

Figure 8. Shu mutants and GEFS ${ }^{+}$flies exhibit a heat-induced seizure phenotype that is suppressed by lithium administration. $\boldsymbol{A}_{\text {, }}$ Individual flies were put into glass vials that were submerged in a water bath $\left(40^{\circ} \mathrm{C}\right)$ for 2 min. Each fly was examined for seizure status (seizing or not seizing) every $5 \mathrm{~s}$. Three independent experiments were carried out, and 10-30 flies were analyzed in each experiment. The average percentages of seizing flies at each time point ( \pm SEM) are shown for Shu $(S h u /+)$ and para ${ }^{\text {GEFS }}+$ mutants (homozygotes and heterozygotes). Shu mutants showed a heat-induced seizure phenotype similar to, but much more robust than, that of para ${ }^{G E F S+}$ mutants. The average percentages of seizing flies at each time point ( \pm SEM) are shown for Shu mutants at $37^{\circ} \mathrm{C}(\boldsymbol{B})$, para $^{G E F S}+$ mutants (homozygotes) at $40^{\circ} \mathrm{C}(\boldsymbol{C})$, and para ${ }^{D S}$ mutants (homozygotes) at $38^{\circ} \mathrm{C}(\boldsymbol{D})$ after treatment with food with $(+)$ or without $(-)$ $100 \mathrm{~mm} \mathrm{LiCl}$. Three independent experiments were carried out, and 27-30 flies were analyzed in each experiment. Control flies (CS or the genetic background strain for para ${ }^{G E F S+}$ and para ${ }^{D S}$ flies) did not seize under these conditions. LiCl treatment significantly suppressed the heat-induced seizure phenotype of Shu and GEFS ${ }^{+}$mutants (two-way repeated-measures ANOVA, Holm-Sidak multiple comparisons, $* * * p<0.001)$. $\boldsymbol{E}$. Time required for control $(n=73)$ and $100 \mathrm{~mm}$ lithium-treated $(n=46)$ parats ${ }^{\text {ts }}$ mutants to become paralyzed at $34^{\circ} \mathrm{C}$. $\mathrm{LiCl}$ treatment significantly enhanced the heat-induced paralysis phenotype. $\boldsymbol{F}$, Time required for control $(n=51)$ and $100 \mathrm{~mm}$ lithium-treated $(n=56)$ para ${ }^{\text {sss } 1}$ mutants to recover from mechanical shock-induced paralysis. LiCl-treated para $^{\text {bss } 1}$ mutants displayed reduced recovery time. Mann-Whitney $U$ test. $* * * p<0.001$. 
ature lower than para ${ }^{\text {GEFS }+}$ mutants (Schutte et al., 2014). We examined the heat-induced phenotype of para ${ }^{D S}$ with or without feeding $100 \mathrm{~mm}$ lithium and found that lithium had no rescue effect (Fig. 8D). Likewise, lithium treatment did not lead to phenotypic improvement in para $^{\text {ts } 1} \mathrm{mu}$ tants. Rather, parats ${ }^{t s}$ mutants paralyzed in shorter time at high temperature when they were treated with lithium (Fig. $8 E$ ). In contrast, para ${ }^{\text {bss } 1}$ mutants were found to recover from mechanical shock-induced paralysis more rapidly when they were fed with lithium-containing food (Fig. 8F). In summary, among para mutant alleles examined in this study, lithium improved the phenotypes of Shu, paraGEFS $^{+}$, and para ${ }^{b s s 1}$ but not those of para ${ }^{D S}$ and para ${ }^{\text {ts } 1}$.

\section{Effects of lithium on abnormal seizure-like discharge phenotypes of Shu mutants}

The apparent behavioral improvement after lithium treatment prompted us to examine DLM activity phenotypes of Shu mutants in this context to determine how each was affected. We compared flies fed $50 \mathrm{~mm} \mathrm{LiCl}$ to those receiving control food and found that $\mathrm{LiCl}$ feeding influenced only selected electrophysiological phenotypes. For instance, it did not significantly reverse the characteristic spontaneous DLM activity seen in Shu flies (mean spike rates for control vs. $\mathrm{LiCl}$ fed: $0.97 \mathrm{~Hz}, n=8$, vs. 0.93 $\mathrm{Hz}, n=10, p=0.36$, rank sum test). However, for ECS-triggered discharges, the number of DLM spikes per discharge was reduced in $\mathrm{LiCl}$-fed Shu flies compared with controls (Fig. 9A). At a stimulus intensity of $80 \mathrm{~V}$, $\mathrm{LiCl}$-fed Shu flies displayed discharges that were significantly milder in terms of spike count compared with control Shu flies (Fig. 9B; $p<0.05$ ). A tendency of reduced spike numbers was observed at $60-\mathrm{V}$ stimulation, although the difference did not reach statistical significance. Therefore, our electrophysiological observations were consistent with the behavioral evidence that $\mathrm{LiCl}$ feeding can improve aspects of the seizure phenotypes of Shu flies.

Behavioral suppression of adult Shu mutants required feeding of lithium for a few days to observe chronic improvements (Williamson, 1982). Similarly, DLM physiology also indicated a lack of acute effects immediately after lithium administration. To directly assess the acute effects of lithium application, we used the larval neuromuscular preparation and observed action potential and neuromuscular transmission. In contrast to wild-type larvae, which did not display spontaneous EJPs with motor axons severed from the CNS (Fig. 9C), the surviving thirdinstar Shu/Shu larvae displayed extreme hyperexcitability, as indicated by spontaneous discharges of EJPs, correlated with bursting of motor axon action potentials, known to be mediated by para $\mathrm{Na}_{\mathrm{v}}$ channels (Fig. 9D). Addition of $1 \mathrm{~mm} \mathrm{LiCl}$ to the saline did not cause acute suppression in excitability (abnormal spontaneous EJPs persisted up to $20 \mathrm{~min}$; Fig. 9E). This concentration of lithium is approximately comparable to the internal concentration after $\mathrm{LiCl}$ feeding to adult flies with $100 \mathrm{~mm}$ in the medium (Padiath et al., 2004; Dokucu et al., 2005). Effective serum lithium concentrations for treating patients with BPD are also in a range of $\sim 1 \mathrm{~mm}$ (Severus et al., 2008). In classic studies,
$\mathrm{Li}^{+}$is known to block the $\mathrm{Na}^{+} / \mathrm{K}^{+}$ATPase pump but can also serve as a highly efficient charge carrier through $\mathrm{Na}_{v}$ channels, with permeability higher than $\mathrm{Na}^{+}$(Hille, 2001). We replaced $\mathrm{Na}^{+}$with $\mathrm{Li}^{+}$in saline $(70 \mathrm{~mm})$ and found that this drastic treatment did not cause any substantial acute effect on hyperexcitability. Further, even after prolonged incubation (up to $20 \mathrm{~min}$ ), it only led to a new pattern of extreme hyperexcitability, i.e., giant plateaued EJPs (not shown), reminiscent of those in eag Sh hyperexcitable $\mathrm{K}^{+}$ channel double mutants caused by high-frequency bursting of motor axon action potentials (Ganetzky and Wu, 1982). Consistently, $\mathrm{LiCl}$ at 1 or $70 \mathrm{~mm}$ did not produce any acute effect on wild-type larvae to generate spontaneous EJPs (Fig. 9C).

\section{Effects of lithium treatment on gene expression in the adult heads}

Our findings suggested that lithium's suppressive effect on Shu phenotypes is not due to acute actions of lithium but rather through long-term physiological adjustments to lithium treatment. Such adjustments possibly involve alterations in gene expression. To explore this possibility, we performed microarray analysis and investigated the effect of the Shu mutation and lithium treatment on genome-wide gene expression in adult heads. Gene expression profiles were compared between genotypes (wild-type and Shu) and treatment (with or without lithium treatment) using Affymetrix GeneChip Drosophila Genome 2.0 Arrays as described in our previous study (Kasuya et al., 2009b). Three biological replicates were tested for each condition and showed high correlation coefficients $(R>0.93)$, indicating that the experimental data were sufficiently reproducible and reliable.

When gene expression profiles were compared between Shu mutants and genetically matched wild-type flies, 17 genes displayed a significant difference $(p<0.05$, Welch $t$-test) in transcript levels with a fold change $>2$ (Table 4). Among them, 14 and three genes were up- and downregulated in Shu mutants, respectively. Intriguingly, seven of the 14 upregulated genes are directly involved in the innate immune response (Table 4). These include six genes encoding for antimicrobial peptides (AMPs; Lemaitre and Hoffmann, 2007): Diptericin B (DptB), Attacin A $(A t t A)$, Attacin B (AttB), Attacin C (AttC), Cecropin B (CecB), and Cecropin C (CecC). PGRP-SB1, another upregulated gene in $S h u$, encodes for a peptidoglycan recognition protein that functions upstream of the signaling cascades regulating the systemic production of AMPs (Lemaitre and Hoffmann, 2007). In addition to these bona fide immune genes, CG42807 and CG32368 were significantly upregulated in Shu. Although the function of these genes is not known, they were reported as two of the most upregulated genes in response to the endogenous presence of microbiota. They are tentatively annotated to encode small peptides, potentially serving as novel immune effectors (Broderick et al., 2014). Furthermore, one of the three calcineurin isoforms, calcineurin $A$ at 14F (CanA-14F) was upregulated in Shu. CanA-14F, along with the other two calcineurin genes in Drosophila, has been shown to play a role in innate immune 


\section{$0 \mathrm{mM} \mathrm{LiCl}$}

$40 \mathrm{~V}$

$60 \mathrm{~V}$

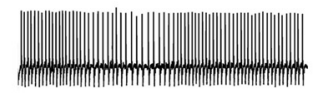

$80 \mathrm{~V}$

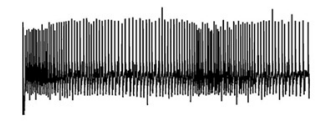

B

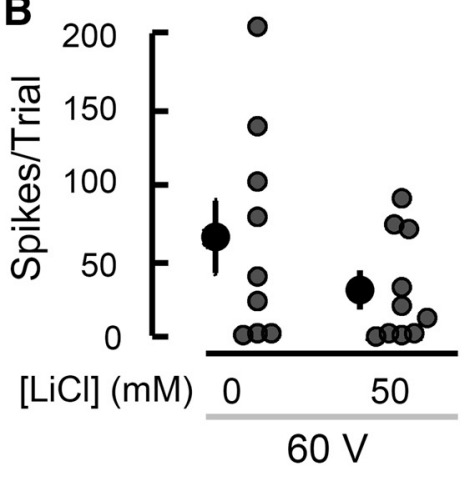

C
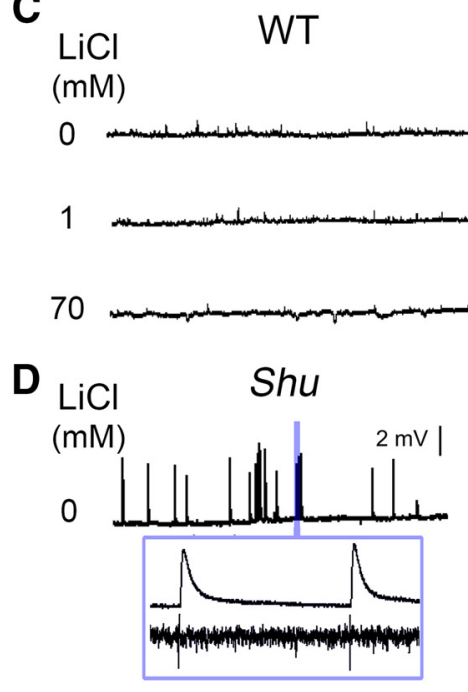

50 mM LiCl

$\checkmark$
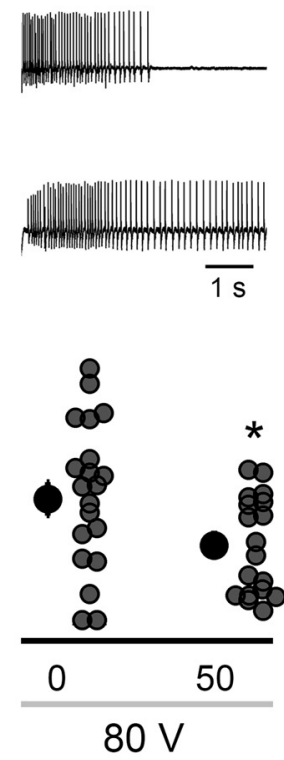

E
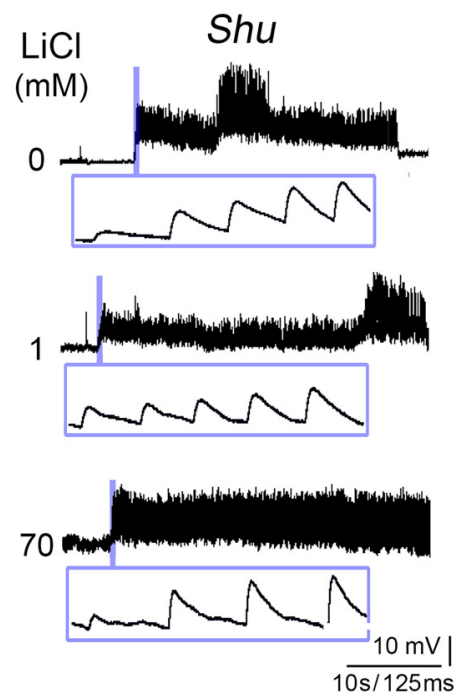

Figure 9. Chronic and acute effects of lithium on the severity of electrophysiological phenotypes of Shu mutant adults and larvae. $\boldsymbol{A}$, Sample traces of ECS discharges (stimulation voltage as indicated) in control Shu/+ flies (0 mm) and lithium-treated Shu/+ flies (50 $\mathrm{mm})$. B, Feeding Shu/+ flies LiCl-supplemented food reduced ECS-triggered spikes per discharge in Shu/+ flies. At 60-V stimulation, the trend was not significant $(p=0.24)$, whereas at $80 \mathrm{~V}$, the ECS discharges were significantly reduced in lithium-treated Shu/+ flies (*p $<0.05$, Kruskal-Wallis one-way ANOVA, rank-sum post hoc test). $\boldsymbol{C}$, Acute extracellular LiCl application in wild-type larvae did not evoke spontaneous EJP activities ( $<10 \mathrm{~min}$ ). 1 and $70 \mathrm{~mm} \mathrm{LiCl}$ was added, with $\mathrm{NaCl}$ levels adjusted to maintain ionic strength. All larval recordings were done with extracellular $\mathrm{Ca}^{2+}$ at $0.5 \mathrm{~mm} . \boldsymbol{D}$, Shu homozygous larvae displayed spontaneous discharges of EJPs, associated with motor axon firing (5-20 Hz). Inset, Individual EJPs were coupled with a motor axon action potential. E, Representative traces of Shu neuromuscular activity upon extracellular application of $\mathrm{Li}^{+}$at 1 and 70 mM. The spontaneous firing phenotype did not weaken upon application of LiCl. Inset, Expanded EJP traces at the onset of spontaneous activities.

signaling (Dijkers and O'Farrell, 2007; Li and Dijkers, 2015). Upregulation of immune gene expression was also observed in two seizure-prone para knock-in mutants, para ${ }^{D S}$ and para ${ }^{G E F S+}$. They displayed elevated expression of $A t t C, C e c C, D p t B$, and PGRP-SB1. However, unlike $S h u$, these mutants did not show higher expression of AttA and CanA-14F compared with genetically matched control flies (Fig. 10). 
Table 4. List of genes whose expression level is significantly altered by the Shu mutation. ${ }^{a}$

\begin{tabular}{|c|c|c|c|c|}
\hline Gene symbol & Cytogenetic location & Fold change & $p$-value ${ }^{\mathrm{b}}$ & Function ${ }^{c}$ \\
\hline DptB & $55 \mathrm{~F} 8$ & $\uparrow 12.2$ & 0.0343 & Defense response (antibacterial peptide) \\
\hline AttC & 50A3 & $\uparrow 8.94$ & 0.0471 & Defense response (antibacterial peptide) \\
\hline $\mathrm{CecC}$ & 99E2 & $\uparrow 8.22$ & 0.0423 & Defense response (antibacterial peptide) \\
\hline AttB & $51 \mathrm{C1}$ & $\uparrow 7.99$ & 0.0170 & Defense response (antibacterial peptide) \\
\hline CG31809 & 36B2 & $\uparrow 6.57$ & 0.0009 & Steroid dehydrogenase activity \\
\hline AttA & $51 C 1$ & $\uparrow 6.31$ & 0.0172 & Defense response (antibacterial peptide) \\
\hline Ste12DOR & 12D2 & $\uparrow 3.33$ & 0.0342 & Protein kinase CK2 activity \\
\hline CecB & 99E2 & $\uparrow 3.17$ & 0.0159 & Defense response (antibacterial peptide) \\
\hline$P G R P-S B 1$ & $73 \mathrm{C1}$ & $\uparrow 2.78$ & 0.0300 & Defense response (peptidoglycan binding) \\
\hline CG42807 & $50 \mathrm{~B} 2$ & $\uparrow 2.31$ & 0.0246 & Unknown \\
\hline CanA-14F & $14 \mathrm{~F}$ & $\uparrow 2.21$ & 0.0109 & Protein serine/threonine phosphatase activity \\
\hline CG32368 & $66 \mathrm{~A} 19$ & $\uparrow 2.20$ & 0.0028 & Unknown \\
\hline Сср84Aa & $84 \mathrm{~A}$ & $\uparrow 2.13$ & 0.0008 & Structural constituent of chitin-based cuticle \\
\hline CG31272 & $86 C 5$ & $\uparrow 2.04$ & 0.0283 & Transporter/lipase activity \\
\hline CG9377 & 34B7 & $\downarrow 14.3$ & 0.0488 & Serine-type endopeptidase activity \\
\hline CG31116 & 86F8 & $\downarrow 3.57$ & 0.0163 & Voltage-gated chloride channel activity \\
\hline Nox & 53B3 & $\downarrow 2.28$ & 0.0176 & Electron carrier activity; oxidoreductase activity \\
\hline
\end{tabular}

aGenes that were detected on all three chips for either wild-type (Kasuya et al., 2009b) or Shu RNA samples and differentially regulated in Shu with a fold change $>2$ and $P<0.05$. Gene ranking is based on amount of fold change. 'betermined by Welch's $t$-test (see Materials and Methods). 'Based on FlyBase.

We next examined whether lithium treatment has any effect on elevated levels of immune gene expression in Shu. As shown in Figure $11 A$ and $B$, treatment with lithium had a general propensity to normalize expression of immune-related genes, although CanA-14F transcript levels in Shu remained higher than those in wild-type flies even after lithium treatment. Quantitative analysis of RTPCR results confirmed that AMP genes and PGRP-SB1 were down-regulated by lithium treatment in Shu mutants but not in the wild-type flies (Fig. 11C).

We analyzed microarray data to further assess the effect of lithium on genome-wide gene expression in Shu. When a comparison was made between Shu mutants with and without lithium treatment, 20 and 5 genes were upand down-regulated by lithium with $p<0.05$ and a fold change $>2$ (Table 5). Using similar criteria, we previously reported that 11 genes were most significantly upregulated by lithium treatment in wild-type flies (Kasuya et al., 2009b). Noticeably, 9 of the 11 upregulated genes in wild-type flies were also found to be upregulated in Shu.
These include genes potentially involved in amino acid transport and metabolism (Lithium-inducible SLC6 transporter/List and CG1673), detoxification and stress response (CG5999 and Activity-regulated cytoskeleton associated protein 1/Arc1), folate-dependent metabolism and ROS regulation (NAD-dependent methylenetetrahydrofolate dehydrogenase/Nmdmc), and oxidation-reduction process (Cyp309a1; Flybase). Although lithiuminducible genes are largely shared by Shu mutants and wild-type flies, none of the significantly downregulated genes were found to be in common (Kasuya et al., 2009b). The five genes downregulated by lithium in Shu include two antibacterial or antifungal peptide genes (Diptericin B/DptB and Metchnikowin/Mtk) and two oxidoreductase genes (deadhead/dhd and CG5653; Flybase).

We also applied a DAVID functional annotation tool (https://david.ncifcrf.gov/tools.jsp) to identify biological pathways likely associated with changes in lithiuminduced gene expression. Using less stringent criteria (false discovery rate $<0.5$ and fold change $>1.2$ ) than the

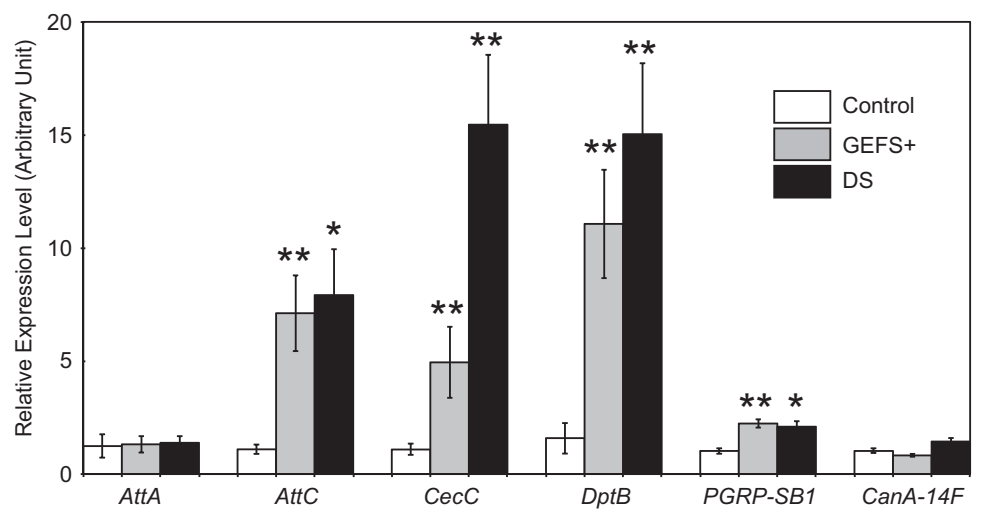

Figure 10. Expression of innate immune response genes is upregulated in para ${ }^{G E F S+}$ and para ${ }^{D S}$ mutants. Expression levels of the selected innate immune response genes were examined in control flies and two para knock-in mutants, paraGEFS+ and para ${ }^{D S}$, by quantitative real-time RT-PCR. Data are normalized transcript levels presented as mean \pm SEM of five to eight independent experiments. $* p<0.05 ; * * p<0.001$. 
A

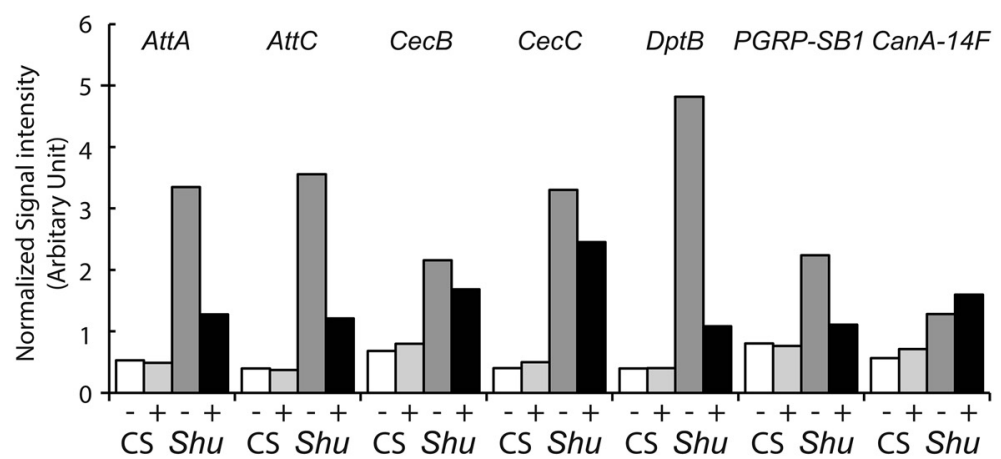

B
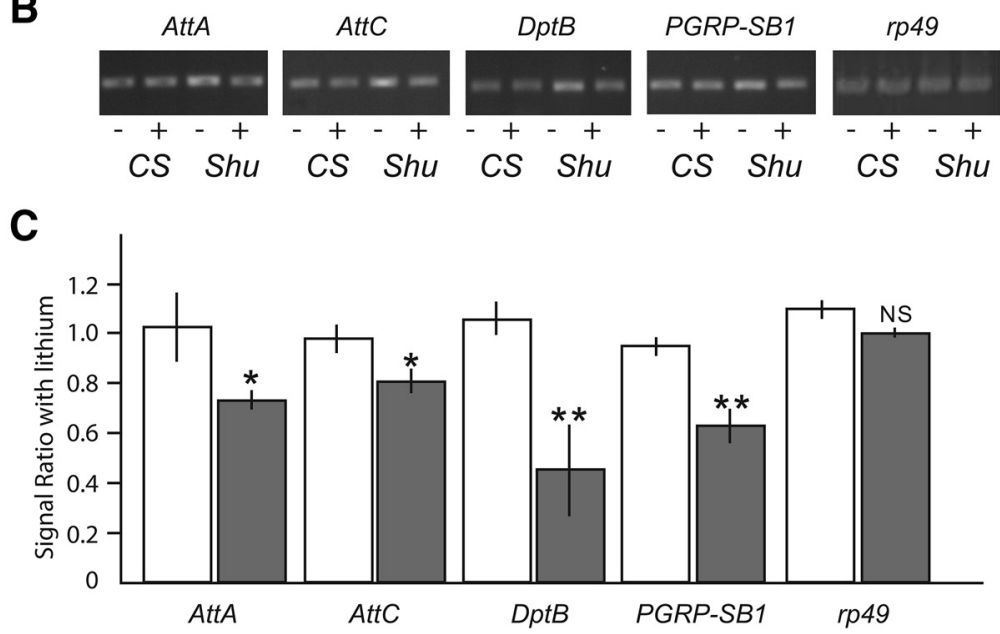

Figure 11. Lithium suppresses the increased expression of innate immune response genes in Shu mutants. $\boldsymbol{A}$, Expression levels of innate immune response genes and CanA-14F in wild-type females from microarray analysis were compared with those in Shu mutants with or without $50 \mathrm{~mm}$ lithium treatment for $24 \mathrm{~h}$. Data are presented as normalized average signal intensities of three biological replicates for each condition. Expression levels of the selected innate immune response genes were examined by RT-PCR in wild-type and Shu mutants with or without $50 \mathrm{~mm}$ lithium treatment for $24 \mathrm{~h}$. A representative agarose gel $(\boldsymbol{B})$ and ratios between transcript levels in control and lithium-treated flies based on pixel intensity of the bands $(\boldsymbol{C})$ are shown (CS, open bar; Shu/+, closed bar). Data are mean \pm SEM of three independent experiments. $* p<0.05 ; * * p<0.001$; NS, not significant.

aforementioned analysis, 158 genes were identified as differentially regulated genes in Shu with and without lithium treatment. Analysis using the DAVID functional annotation chart program identified 19 partially redundant gene ontology (GO) term entries as highly enriched in a list of lithium-responsive genes with $p<10^{-5}$ (Table 6). Interestingly, amino acid metabolism represented by multiple GO terms (e.g., 0008652, 0046394, 0006564, 0009066) stood out as the biological process most significantly affected by lithium treatment. Genes involved in carbohydrate metabolism and redox reactions were also found to be strongly affected when Shu mutants were treated with lithium.

\section{Discussion}

In this study, we identified Shu, a Drosophila mutation causing severe behavioral defects, as a novel hypermorphic allele of the $\mathrm{Na}_{\mathrm{v}}$ channel gene para (Fig. 3). The notion that the Shu mutation is hypermorphic is based on Shu's morphological, electrophysiological, and behavioral phenotypes (Figs. 1 and 2) as well as the observation that Shu phenotypes were substantially suppressed when para function was reduced using para hypomorphs (Fig. 5) or para-RNAi (Fig. 6). These results suggest that the Shu $\mathrm{Na}_{\mathrm{v}}$ channels cause an increase in sodium currents, and that this defect is compensated by reduced para function, leading to a more balanced neuronal output.

We were able to at least partly recapitulate Shu phenotypes by driving expression of $\mathrm{Shu} \mathrm{Na}_{v}$ channels in wildtype flies (Fig. 4). However, the effect of the Shu transgene was mild when the motor neuron-positive driver C164Gal4 was used (Fig. 4), and there was little effect with a pan-neuronal driver elav-Gal4. Our result somewhat resembles that of a previous attempt to reproduce the para $^{\text {bss } 1}$ mutant phenotype with pan-neuronal expression of the para ${ }^{\text {bss } 1}$ transgene (Parker et al., 2011), where only a small subset $(1.6 \%)$ of wild-type flies expressing the para $^{\text {bss } 1}$ transgene displayed the bang-sensitive phenotype. Although the reasons underlying the weak effect of these mutant transgenes remain unknown, a lack of alternative splicing may contribute. Previous studies revealed that 27-29 distinct para splice variants exist, and that they are functionally diverse (Olson et al., 2008; Lin et al., 
Table 5. List of genes whose expression level is significantly altered by lithium treatment in Shu mutants. ${ }^{a}$

\begin{tabular}{|c|c|c|c|c|}
\hline Gene symbol & Cytogenetic location & Fold change & $p$-value & Function $^{c}$ \\
\hline List & $55 \mathrm{E} 10$ & $\uparrow 7.11$ & 0.0001 & Sodium:neurotransmitter symporter \\
\hline CG5999 & $87 \mathrm{C} 8$ & $\uparrow 6.55$ & 0.0462 & UDP-glucosyltransferase activity \\
\hline Arc1 & $50 F 6$ & $\uparrow 4.67$ & 0.0002 & Stress response \\
\hline CG7763 & $47 \mathrm{~F} 11$ & $\uparrow 3.25$ & $5.3 \times 10^{-6}$ & C-type lectin \\
\hline MtnD & $92 \mathrm{~F} 1$ & $\uparrow 3.14$ & 0.0445 & Metal homeostasis \\
\hline Nmdmc & $85 C 3$ & $\uparrow 2.92$ & 0.0033 & NAD-dependent methylenetetrahydrofolate dehydrogenase activity \\
\hline CG1673 & $11 \mathrm{~F} 1$ & $\uparrow 2.90$ & 0.0026 & Branched-chain amino-acid aminotransferase activity \\
\hline Bin1 & $89 B 7$ & $\uparrow 2.74$ & 0.0126 & Histone deacetylase complex \\
\hline Hsp22 & $67 \mathrm{~B} 2$ & $\uparrow 2.59$ & 0.0003 & Response to oxidative stress \\
\hline Lsp1 $1 \gamma$ & $61 \mathrm{~A} 6$ & $\uparrow 2.42$ & 0.0094 & Nutrient reservoir activity \\
\hline Сур309а1 & 22F4-23A1 & $\uparrow 2.29$ & 0.0034 & Cytochrome P450; oxidation-reduction process \\
\hline CG11425 & 79E4 & $\uparrow 2.28$ & 0.0055 & hydrolase \\
\hline CG15784 & $4 \mathrm{~F} 10$ & $\uparrow 2.26$ & 0.0014 & Unknown \\
\hline Blos2 & $36 \mathrm{C} 11$ & $\uparrow 2.19$ & 0.0415 & Biogenesis of lysosome-related organelles \\
\hline $\mathrm{NimC2}$ & 34E5 & $\uparrow 2.17$ & 0.0162 & Phagocytosis \\
\hline Cpr64Ac & $64 \mathrm{~A} 10$ & $\uparrow 2.15$ & 0.0023 & Cuticular protein \\
\hline Ahcy13 & $13 \mathrm{C3}$ & $\uparrow 2.14$ & 0.0001 & Adenosylhomocysteinase activity \\
\hline CG34136 & 39A1 & $\uparrow 2.07$ & 0.0137 & Unknown \\
\hline$A O \times 1$ & $88 F 7$ & $\uparrow 2.06$ & 0.0042 & Aldehyde oxidase activity \\
\hline Ama & $84 \mathrm{~A} 5$ & $\uparrow 2.04$ & 0.0126 & Axon pathfinding \\
\hline dhd & $4 \mathrm{~F} 4$ & $\downarrow 6.33$ & 0.0156 & Thioredoxin \\
\hline DptB & 55F8 & $\downarrow 4.44$ & 0.0487 & Defense response (antibacterial peptide) \\
\hline Mtk & $52 \mathrm{~A} 1$ & $\downarrow 2.85$ & 0.0371 & Defense response (antimicrobial peptide) \\
\hline CG7227 & 28D3 & $\downarrow 2.46$ & 0.0235 & Defense response (scavenger receptor activity) \\
\hline CG5653 & 66E5 & $\downarrow 2.18$ & 0.0083 & Amine oxidase activity \\
\hline
\end{tabular}

${ }^{a}$ Genes that were detected on all three chips for RNA samples of Shu with or without lithium treatment and differentially regulated under these conditions with a fold change $>2$ and $p<0.05$. Gene ranking is based on amount of fold change. 'Determined by Welch's $t$-test (see Materials and Methods). 'Based on FlyBase.

2009). In our study and that of Parker et al. (2011), the cDNA of the $\mathrm{Na}_{v} 1-1$ para isoform, which is presumably the most common splice variant in adult flies (Olson et al., 2008; Lin et al., 2009), was utilized to construct the Shu and para ${ }^{b s s}$ transgenes. To completely mimic the effects of these dominant para mutations, the transgenes may need to be expressed, in specific cell types, as certain splice variants.

Importantly, as originally reported by Williamson (1982), we observed suppression of the seizure-like phenotypes of Shu when the mutants were fed lithium-containing food (Fig. 7). In this study, we also demonstrated that GF motor outputs of Shu mutants exhibit hyperexcitable, seizurelike discharges and that lithium partially rescues these phenotypes as well (Fig. 9). Our results show that lithium can improve physiological as well as behavioral defects originally caused by aberrant sodium channel function. Consistently, lithium had a rescue effect on the heatinduced seizure phenotype of para ${ }^{\text {GEFS+ }}$ and the bangsensitive phenotype of para ${ }^{\text {bss1 }}$ (Fig. 8C, F). Based on their

Table 6. Functional annotation chart of selected lithium-responsive genes analyzed by DAVID.

\begin{tabular}{llll}
\hline Enriched Gene Ontology (GO) annotation terms & GO ID & $p_{\text {-value }}^{\text {a }}$ & Fold enrichment $^{-8}$ \\
Cellular amino acid biosynthetic process & 0008652 & $5.1 \times 10^{-8}$ & 21.7 \\
Carboxylic/organic acid biosynthetic process & $0046394 / 0016053^{\mathrm{b}}$ & $8.6 \times 10^{-8}$ & 12.3 \\
Amine biosynthetic process & 0009309 & $1.0 \times 10^{-7}$ & 15.0 \\
Cofactor binding & 0048037 & $5.5 \times 10^{-7}$ & 5.4 \\
Oxidation-reduction process & 0055114 & $1.8 \times 10^{-6}$ & 3.0 \\
Lipid particle & 0005811 & $2.4 \times 10^{-6}$ & 4.9 \\
L-serine biosynthetic process & 0006564 & $7.7 \times 10^{-6}$ & 78.6 \\
Hexose metabolic process & 0019318 & $1.0 \times 10^{-5}$ & 8.3 \\
Aspartate family amino acid metabolic process & 0009066 & $1.6 \times 10^{-5}$ & 30.2 \\
L-serine metabolic process & 0006563 & $1.9 \times 10^{-5}$ & 62,9 \\
Monosaccharide metabolic process & 0005996 & $2.7 \times 10^{-5}$ & 7.3 \\
Mitochondrion & 0005739 & $2.8 \times 10^{-5}$ & 2.9 \\
Cellular nitrogen compound biosynthetic process & 0044271 & $3.3 \times 10^{-5}$ & 4.4 \\
Serine family amino acid metabolic process & 0009069 & $3.8 \times 10^{-5}$ & 24.6 \\
IMP biosynthetic/metabolic process & $0006188 / 0046040^{c}$ & $6.5 \times 10^{-5}$ & 44.9 \\
Serine family amino acid biosynthetic process & 0009070 & $6.5 \times 10^{-5}$ & 44.9 \\
Transaminase activity & 0008483 & $7.4 \times 10^{-5}$ & 20.8
\end{tabular}

${ }^{a} p$-value for a modified Fisher exact test (EASE score). ${ }^{b, c}$ The identical genes are assigned to these terms for the Drosophila genome. 
Table 7. Primers used for PCR experiments.

\begin{tabular}{|c|c|c|}
\hline Gene symbol & Forward primer $\left(5^{\prime}-3^{\prime}\right)$ & Reverse primer $\left(5^{\prime}-3^{\prime}\right)$ \\
\hline \multicolumn{3}{|c|}{ Real-time RT-PCR } \\
\hline AttA & TGGCAATCCCAACCACAA & CATTGTTGTAGGCCAAAGTTCC \\
\hline AttC & AACTCCCGATCACCATGTTATT & CAGGCCGTGTCCATGATT \\
\hline $\mathrm{CecC}$ & CGGTTGGCTGAAGAAACTTG & GCAATTCCCAGTCCTTGAATG \\
\hline DptB & ACTGGCATATGCTCCCAATTT & TCAGATCGAATCCTTGCTTTGG \\
\hline PGRP-SB1 & GATGAACACATCAACGGCAATTA & TGCTGCGTGGTTCAATCT \\
\hline rp49 & CCAGTCGGATCGATATGCTAAG & CCGATGTTGGGCATCAGATA \\
\hline \multicolumn{3}{|c|}{ Semiquantitative RT-PCR } \\
\hline AttA & ACGGTCCACTCGTCCACTTG & CAATGCTGGTCATGGTGCCTC \\
\hline AttC & CAGATCGGTCTGGCCCTTGAA & TCATGGACACGGCCTGGAAC \\
\hline DptB & TGTAGCTTCTGAAGTGCCCT & TTCATTGGACTGGCTTGTGC \\
\hline PGRP-SB1 & TTGTCTGCCGATGACCGAACA & TCTATCCGCCAATGCССTGC \\
\hline rp49 & TTCGCTAAGCAGTAGCTGCGAC & GTTAACACGCAGGCGACGGAA \\
\hline
\end{tabular}

electrophysiological phenotypes, both para ${ }^{G E F S+}$ and para $^{\text {bss } 1}$ are considered to be para gain-of-function alleles (Parker et al., 2011; Sun et al., 2012). In contrast, lithium does not seem to improve the phenotypes of two para loss-of-function alleles, para ${ }^{D S}$ and para $^{\text {ts1 }}$ (Fig. 8D, E). This apparent correlation between types of $\mathrm{Na}_{v}$ channel mutations (i.e., gain- and loss-of-function) and the effects of lithium suggest that lithium may preferentially improve defects caused by aberrantly activated $\mathrm{Na}_{v}$ channels.

Interestingly, many antiepileptic drugs targeting $\mathrm{Na}_{\mathrm{v}}$ channels, such as lamotrigine, are effective for BPD (Landmark, 2008). This therapeutic regimen for BPD suggests that its pathophysiology may be influenced by abnormal $\mathrm{Na}_{v}$ channel function. Further evidence for the connection between BPD and $\mathrm{Na}_{v}$ channels comes from genome-wide association studies, which have implicated ankyrin-G (ANK3) as a potential risk factor for BPD (Ferreira et al., 2008). ANK3 encodes an adaptor protein that regulates $\mathrm{Na}_{v}$ channel assembly (Poliak and Peles, 2003). Likewise, a gene expression study in the postmortem brains of BPD patients found that the $\alpha$-and $\beta$-subunits of the voltage-gated type I sodium channel genes were upregulated (Smolin et al., 2012). Overall, these data provide support for the notion that the dysregulation of $\mathrm{Na}_{\mathrm{v}}$ channel function may play a role in the etiology of BPD, and that some of the most effective pharmacological therapies for this disorder may counteract the effect of aberrant $\mathrm{Na}_{v}$ channel activity.

Lithium is commonly thought to elicit its moodstabilizing effect by inhibiting GSK-3 $\beta$, IMPase, or IPPase (Manji and Lenox, 1998; Phiel and Klein, 2001; Lenox and Wang, 2003; Machado-Vieira et al., 2009). However, our experiments did not yield results that directly connect lithium's rescue effect with these enzymes. For instance, pharmacological inhibition of GSK-3 $\beta$ using AR-A014418, which was shown to reduce tau-induced pathology by inhibiting GSK-3 $\beta$ (Mudher et al., 2004), did not suppress behavioral phenotypes of Shu. The median values of percentage of time spent inside were 42.8 and $47.9 \%$ for control $(n=37)$ and AR-A014418-treated $(n=46 ; p>$ $0.05)$ flies, respectively. Likewise, feeding Shu mutants with L-690,330, which is known to be $\sim 1000$-fold more potent than lithium in inhibiting IMPase (Atack et al., 1993), did not lead to phenotypic suppression either. The median values of percentage of time spent inside were 43.4 and $39.4 \%$ for control $(n=19)$ and L-690,330treated $(n=23 ; p>0.05)$ flies, respectively. These negative data with the enzyme inhibitors suggest that lithium may act independently of GSK-3 $\beta$ and inositol signaling in exerting its rescue effect on Shu mutants.

Early voltage-clamp studies demonstrated that the permeability of $\mathrm{Na}_{\mathrm{v}}$ channels to $\mathrm{Li}^{+}$is nearly identical to their permeability to $\mathrm{Na}^{+}$itself $\left(P_{\mathrm{Li}} / P_{\mathrm{Na}}=0.93\right.$; Hille, 1972; Campbell, 1976). In bovine adrenal chromaffin cells, $\mathrm{Li}^{+}$ was shown to inhibit radioactive $\mathrm{Na}^{+}$influx through veratridine-activated sodium channels, independently of GSK-3 $\beta$ (Yanagita et al., 2007). Such observations raised the possibility that lithium may suppress activity of Shu $\mathrm{Na}_{v}$ channels to confer a rescue effect. However, direct application of lithium did not cause acute suppression of hyperexcitability of motor neurons displayed by Shu larvae (Fig. 9E). Moreover, total replacement of $\mathrm{Na}^{+}$with $\mathrm{Li}^{+}$ did not alter the hyperexcitability phenotype in the larval motor axon (Fig. 9E). Our results are consistent with the previous observation that $\mathrm{Li}^{+}$, like ouabain, can enhance neuromuscular excitability in wild-type larvae via inhibition of $\mathrm{Na}^{+} / \mathrm{K}^{+}$ATPase (Jan and Jan, 1978), in contrast to the suppression effect of chronic lithium feeding to Shu mutants. Furthermore, a recent report demonstrates interesting effects of long-term lithium treatment of induced pluripotent stem cells derived from lithium-responsive BPD patients. The differentiated neurons from such patients display hyperexcitability that can be suppressed after 1-week incubation in lithium-containing culture medium. A reduction in neuronal firing is coupled with a decrease in $\mathrm{Na}^{+}$and $\mathrm{K}^{+}$currents, consistent with a longterm physiological readjustment of neuronal excitability mechanisms (Mertens et al., 2015).

Our microarray and RT-PCR analyses revealed that expression of innate immune response genes is enhanced in the head of Shu mutants and that lithium tends to normalize their expression levels (Table 4, Fig. 11). The correlation between immune gene expression and severity of Shu phenotypes raises the possibility that the innate immune system is involved in manifestation of Shu phenotypes and their modulation by lithium. Changes in immune gene expression were also observed in two other seizure-prone para knock-in mutants (Fig. 10) and are 
associated with genetic suppression of seizure-like phenotypes of Drosophila easily shocked (eas) mutants (Hekmat-Scafe et al., 2005). In addition, experimental and clinical studies have provided accumulating evidence for a strong relationship between an activated innate immune system and the pathophysiology of psychiatric and neurological disorders, including BPD and human epilepsies, as well as in rodent epilepsy models (Granata et al., 2011; Vezzani et al., 2011; Legido and Katsetos, 2014; Elhaik and Zandi, 2015). Recent studies using mice also demonstrated that lithium can attenuate innate immune responses in a GSK-3 $\beta$-independent manner both in vitro and in vivo (Wang et al., 2013).

A combination of microarray and bioinformatics analyses revealed additional genes and biological pathways significantly affected by lithium treatment in Shu. Particularly notable are those related to amino acid metabolism and oxidation-reduction processes (Tables 5 and 6). Interestingly, alterations of brain amino acid metabolism are implicated in the antiepileptic effect of the ketogenic diet (Yudkoff et al., 2001), whereas redox reactions, particularly those involved in oxidative stress, are suggested to play critical roles in initiation and progression of epilepsy (Shin et al., 2011). Future experiments are required to determine whether these biological pathways as well as the innate immune system have functional significance in lithium-dependent improvement of Shu phenotypes caused by abnormal $\mathrm{Na}_{\mathrm{v}}$ channel activity.

Despite several decades of scientific investigation, the exact etiology and the mechanisms of drug action for many psychiatric disorders, such as BPD, remain largely unknown. Attempts to better understand the pathophysiology of these illnesses using animal models, including Drosophila, continue to be a challenge but also prove highly promising (Nestler and Hyman, 2010). Taken together, our results suggest that Shu and other Drosophila sodium channel mutants have the potential to be useful and experimentally amenable tools for elucidating the actions of lithium in the nervous system, and that they may ultimately contribute to an understanding of lithiumresponsive disorders in humans.

\section{References}

Atack JR, Cook SM, Watt AP, Fletcher SR, Ragan Cl (1993) In vitro and in vivo inhibition of inositol monophosphatase by the bisphosphonate L-690,330. J Neurochem 60:652-658. Medline

Benzer S (1967) Behavioral mutants of Drosophila isolated by countercurrent distribution. Proc Natl Acad Sci U S A 58:1112-1119. Medline

Berger Z, Ttofi EK, Michel CH, Pasco MY, Tenant S, Rubinsztein DC, O'Kane CJ (2005) Lithium rescues toxicity of aggregate-prone proteins in Drosophila by perturbing Wnt pathway. Hum Mol Genet 14:3003-3011. CrossRef Medline

Berridge MJ, Downes CP, Hanley MR (1989) Neural and developmental actions of lithium: a unifying hypothesis. Cell 59:411-419. Medline

Berry-Kravis E, Sumis A, Hervey C, Nelson M, Porges SW, Weng N, Weiler IJ, Greenough WT (2008) Open-label treatment trial of lithium to target the underlying defect in fragile $X$ syndrome. J Dev Behav Pediatr 29:293-302. CrossRef Medline

Besson M, Martin JR (2005) Centrophobism/thigmotaxis, a new role for the mushroom bodies in Drosophila. J Neurobiol 62:386-396. CrossRef Medline
Broderick NA, Buchon N, Lemaitre B (2014) Microbiota-induced changes in drosophila melanogaster host gene expression and gut morphology. mBio 5:e01117-e01114. CrossRef Medline

Burg MG, Geng C, Guan Y, Koliantz G, Pak WL (1996) Drosophila rosA gene, which when mutant causes aberrant photoreceptor oscillation, encodes a novel neurotransmitter transporter homologue. J Neurogenet 11:59-79. Medline

Bushey D, Hughes KA, Tononi G, Cirelli C (2010) Sleep, aging, and lifespan in Drosophila. BMC Neurosci 11:56. CrossRef Medline

Cade J (1949) Lithium salts in the treatment of psychotic excitement. Med J Aust 2:349-352. Medline

Campbell DT (1976) lonic selectivity of the sodium channel of frog skeletal muscle. J Gen Physiol 67:295-307. Medline

Chouinard SW, Wilson GF, Schlimgen AK, Ganetzky B (1995) A potassium channel beta subunit related to the aldo-keto reductase superfamily is encoded by the Drosophila hyperkinetic locus. Proc Natl Acad Sci U S A 92:6763-6767. Medline

Dijkers PF, O'Farrell PH (2007) Drosophila calcineurin promotes induction of innate immune responses. Curr Biol 17:2087-2093. CrossRef Medline

Dokucu ME, Yu L, Taghert PH (2005) Lithium- and valproate-induced alterations in circadian locomotor behavior in Drosophila. Neuropsychopharmacology 30:2216-2224. CrossRef Medline

Ehaideb SN, lyengar A, Ueda A, lacobucci GJ, Cranston C, Bassuk AG, Gubb D, Axelrod JD, Gunawardena S, Wu CF, Manak JR (2014) prickle modulates microtubule polarity and axonal transport to ameliorate seizures in flies. Proc Natl Acad Sci U S A 111: 11187-11192. CrossRef Medline

Elhaik E, Zandi P (2015) Dysregulation of the NF-kappaB pathway as a potential inducer of bipolar disorder. J Psychiatr Res 70:18-27. CrossRef Medline

Elkins T, Ganetzky B, Wu CF (1986) A Drosophila mutation that eliminates a calcium-dependent potassium current. Proc Natl Acad Sci U S A 83:8415-8419. Medline

Engel JE, Wu CF (1992) Interactions of membrane excitability mutations affecting potassium and sodium currents in the flight and giant fiber escape systems of Drosophila. J Comp Physiol A 171:93-104. Medline

Engel JE, Wu CF (1998) Genetic dissection of functional contributions of specific potassium channel subunits in habituation of an escape circuit in Drosophila. J Neurosci 18:2254-2267. Medline

Feng Y, Ueda A, Wu CF (2004) A modified minimal hemolymph-like solution, HL3.1, for physiological recordings at the neuromuscular junctions of normal and mutant Drosophila larvae. J Neurogenet 18:377-402. CrossRef Medline

Ferreira MA, et al. (2008) Collaborative genome-wide association analysis supports a role for ANK3 and CACNA1C in bipolar disorder. Nat Genet 40:1056-1058. CrossRef Medline

Frankel AWK, Brousseau GE (1968) Drosophila medium that does not require dried yeast. Drosophila Information Service 43:184

Ganetzky B (1984) Genetic studies of membrane excitability in Drosophila: lethal interaction between two temperature-sensitive paralytic mutations. Genetics 108:897-911. Medline

Ganetzky B, Wu CF (1982) Drosophila mutants with opposing effects on nerve excitability: genetic and spatial interactions in repetitive firing. J Neurophysiol 47:501-514. Medline

Ganetzky B, Wu CF (1983) Neurogenetic analysis of potassium currents in Drosophila: synergistic effects on neuromuscular transmission in double mutants. J Neurogenet 1:17-28. Medline

Ganetzky B, Wu CF (1985) Genes and membrane excitability in Drosophila. Trends Neurosci 8:322-326. CrossRef

Gilestro GF, Cirelli C (2009) pySolo: a complete suite for sleep analysis in Drosophila. Bioinformatics 25:1466-1467. CrossRef Medline

Granata T, Cross H, Theodore W, Avanzini G (2011) Immunemediated epilepsies. Epilepsia 52 Suppl 3:5-11. CrossRef Medline

Greene JC, Whitworth AJ, Kuo I, Andrews LA, Feany MB, Pallanck LJ (2003) Mitochondrial pathology and apoptotic muscle degeneration in Drosophila parkin mutants. Proc Natl Acad Sci U S A 100:4078-4083. CrossRef Medline 
Harcombe ES, Wyman RJ (1977) Output pattern generation by Drosophila flight motoneurons. J Neurophysiol 40:1066-1077. Medline

Haugland FN, Wu CF (1990) A voltage-clamp analysis of genedosage effects of the Shaker locus on larval muscle potassium currents in Drosophila. J Neurosci 10:1357-1371. Medline

Hekmat-Scafe DS, Dang KN, Tanouye MA (2005) Seizure suppression by gain-of-function escargot mutations. Genetics 169:14771493. CrossRef Medline

Hille B (1972) The permeability of the sodium channel to metal cations in myelinated nerve. J Gen Physiol 59:637-658. Medline

Hille B (2001) Ion channels of excitable membranes, 3rd Ed. Sinauer Associates: Sunderland, MA.

Huang DW, Sherman BT, Lempicki RA (2009) Systematic and integrative analysis of large gene lists using DAVID bioinformatics resources. Nat Protoc 4:44-57. CrossRef Medline

Huang Y, Stern M (2002) In vivo properties of the Drosophila inebriated-encoded neurotransmitter transporter. J Neurosci 22: 1698-1708. Medline

Humphreys JM, Duyf B, Joiner ML, Phillips JP, Hilliker AJ (1996) Genetic analysis of oxygen defense mechanisms in Drosophila melanogaster and identification of a novel behavioural mutant with a Shaker phenotype. Genome 39:749-757. CrossRef [Mismatch]

litaka C, Miyazaki K, Akaike T, Ishida N (2005) A role for glycogen synthase kinase-3beta in the mammalian circadian clock. J Biol Chem 280:29397-29402. CrossRef Medline

lyengar A, Wu CF (2014) Flight and seizure motor patterns in Drosophila mutants: simultaneous acoustic and electrophysiological recordings of wing beats and flight muscle activity. J Neurogenet 28:316-328. CrossRef Medline

Jan YN, Jan LY (1978) Genetic dissection of short-term and longterm facilitation at the Drosophila neuromuscular junction. Proc Natl Acad Sci U S A 75:515-519. Medline

Jepson JE, Shahidullah M, Lamaze A, Peterson D, Pan H, Koh K (2012) dyschronic, a Drosophila homolog of a deaf-blindness gene, regulates circadian output and Slowpoke channels. PLoS Genet 8:e1002671. CrossRef Medline

Kamb A, Iverson LE, Tanouye MA (1987) Molecular characterization of Shaker, a Drosophila gene that encodes a potassium channel. Cell 50:405-413. Medline

Kaplan WD, Trout WE 3rd (1969) The behavior of four neurological mutants of Drosophila. Genetics 61:399-409. Medline

Kasuya J, Kaas GA, Kitamoto T (2009a) A putative amino acid transporter of the solute carrier 6 family is upregulated by lithium and is required for resistance to lithium toxicity in Drosophila. Neuroscience 163:825-837. CrossRef Medline

Kasuya J, Kaas G, Kitamoto T (2009b) Effects of lithium chloride on the gene expression profiles in Drosophila heads. Neurosci Res 64:413-420. CrossRef Medline

Klein PS, Melton DA (1996) A molecular mechanism for the effect of lithium on development. Proc Natl Acad Sci U S A 93:8455-8459. Medline

Koh K, Joiner WJ, Wu MN, Yue Z, Smith CJ, Sehgal A (2008) Identification of SLEEPLESS, a sleep-promoting factor. Science 321:372-376. CrossRef Medline

Landmark JC (2008) Antiepileptic drugs in non-epilepsy disorders: relations between mechanisms of action and clinical efficacy. CNS Drugs 22:27-47. CrossRef

Lee J, Wu CF (2002) Electroconvulsive seizure behavior in Drosophila: analysis of the physiological repertoire underlying a stereotyped action pattern in bang-sensitive mutants. J Neurosci 22: 11065-11079. Medline

Lee J, Wu CF (2006) Genetic modifications of seizure susceptibility and expression by altered excitability in Drosophila $\mathrm{Na}(+)$ and $\mathrm{K}(+)$ channel mutants. J Neurophysiol 96:2465-2478. CrossRef Medline

Lee J, Ueda A, Wu CF (2008) Pre- and post-synaptic mechanisms of synaptic strength homeostasis revealed by slowpoke and shaker $\mathrm{K}+$ channel mutations in Drosophila. Neuroscience 154:12831296. CrossRef
Legido A, Katsetos CD (2014) Experimental studies in epilepsy: immunologic and inflammatory mechanisms. Semin Pediatr Neurol 21:197-206. CrossRef Medline

Lemaitre B, Hoffmann J (2007) The host defense of Drosophila melanogaster. Ann Rev Immunol 25:697-743. CrossRef Medline

Lenox RH, Wang L (2003) Molecular basis of lithium action: integration of lithium-responsive signaling and gene expression networks. Mol Psychiatry 8:135-144. CrossRef Medline

Li YX, Dijkers PF (2015) Specific calcineurin isoforms are involved in Drosophila toll immune signaling. J Immunol 194:168-176. CrossRef Medline

Lin WH, Wright DE, Muraro NI, Baines RA (2009) Alternative splicing in the voltage-gated sodium channel DmNav regulates activation, inactivation, and persistent current. J Neurophysiol 102:19942006. CrossRef

Livak KJ, Schmittgen TD (2001) Analysis of relative gene expression data using real-time quantitative PCR and the 2(-Delta Delta C(T)) Method. Methods 25:402-408. CrossRef Medline

Loughney K, Kreber R, Ganetzky B (1989) Molecular analysis of the para locus, a sodium channel gene in Drosophila. Cell 58:11431154. Medline

Machado-Vieira R, Manji HK, Zarate CA Jr. (2009) The role of lithium in the treatment of bipolar disorder: convergent evidence for neurotrophic effects as a unifying hypothesis. Bipolar Disord 11(Suppl 2):92-109. CrossRef

Manji HK, Lenox RH (1998) Lithium: a molecular transducer of moodstabilization in the treatment of bipolar disorder. Neuropsychopharmacology 19:161-166. CrossRef Medline

Marley R, Baines RA (2011) Increased persistent $\mathrm{Na}+$ current contributes to seizure in the slamdance bang-sensitive Drosophila mutant. J Neurophysiol 106:18-29. CrossRef Medline

McBride SM, Choi CH, Wang Y, Liebelt D, Braunstein E, Ferreiro D, Sehgal A, Siwicki KK, Dockendorff TC, Nguyen HT, McDonald TV, Jongens TA (2005) Pharmacological rescue of synaptic plasticity, courtship behavior, and mushroom body defects in a Drosophila model of fragile $X$ syndrome. Neuron 45:753-764. CrossRef

Mertens J, et al. (2015) Differential responses to lithium in hyperexcitable neurons from patients with bipolar disorder. Nature 527: 95-99. CrossRef Medline

Mudher A, Shepherd D, Newman TA, Mildren P, Jukes JP, Squire A, Mears A, Drummond JA, Berg S, MacKay D, Asuni AA, Bhat R, Lovestone S (2004) GSK-3beta inhibition reverses axonal transport defects and behavioural phenotypes in Drosophila. Mol Psychiatry 9:522-530. CrossRef Medline

Nestler EJ, Hyman SE (2010) Animal models of neuropsychiatric disorders. Nat Neurosci 13:1161-1169. CrossRef Medline

Olson RO, Liu Z, Nomura Y, Song W, Dong K (2008) Molecular and functional characterization of voltage-gated sodium channel variants from Drosophila melanogaster. Insect Biochem Mol Biol 38: 604-610. CrossRef Medline

Padiath QS, Paranjpe D, Jain S, Sharma VK (2004) Glycogen synthase kinase 3beta as a likely target for the action of lithium on circadian clocks. Chronobiol Int 21:43-55. Medline

Papazian DM, Schwarz TL, Tempel BL, Jan YN, Jan LY (1987) Cloning of genomic and complementary DNA from Shaker, a putative potassium channel gene from Drosophila. Science 237: 749-753. Medline

Parker L, Padilla M, Du Y, Dong K, Tanouye MA (2011) Drosophila as a model for epilepsy: bss is a gain-of-function mutation in the para sodium channel gene that leads to seizures. Genetics 187:523534. CrossRef Medline

Pavlidis P, Tanouye MA (1995) Seizures and failures in the giant fiber pathway of Drosophila bang-sensitive paralytic mutants. J Neurosci 15:5810-5819. Medline

Pfaffl MW (2001) A new mathematical model for relative quantification in real-time RT-PCR. Nucleic Acids Res 29:e45. Medline

Phiel CJ, Klein PS (2001) Molecular targets of lithium action. Annu Rev Pharmacol Toxicol 41:789-813. CrossRef Medline 
Poliak S, Peles E (2003) The local differentiation of myelinated axons at nodes of Ranvier. Nat Rev Neurosci 4:968-980. CrossRef Medline

Pongs O, Kecskemethy N, Müller R, Krah-Jentgens I, Baumann A, Kiltz HH, Canal I, Llamazares S, Ferrus A (1988) Shaker encodes a family of putative potassium channel proteins in the nervous system of Drosophila. EMBO J 7:1087-1096. Medline

Salkoff LB, Wyman RJ (1983) Ion currents in Drosophila flight muscles. J Physiol 337:687-709. Medline

Scheffer IE, Berkovic SF (1997) Generalized epilepsy with febrile seizures plus. A genetic disorder with heterogeneous clinical phenotypes. Brain 120:479-490. CrossRef

Schutte RJ, Schutte SS, Algara J, Barragan EV, Gilligan J, Staber C, Savva YA, Smith MA, Reenan R, O'Dowd DK (2014) Knock-in model of Dravet syndrome reveals a constitutive and conditional reduction in sodium current. J Neurophysiol 112:903-912.

Senatorov VV, Ren M, Kanai H, Wei H, Chuang DM (2004) Short-term lithium treatment promotes neuronal survival and proliferation in rat striatum infused with quinolinic acid, an excitotoxic model of Huntington's disease. Mol Psychiatry 9:371-385. CrossRef Medline

Severus WE, Kleindienst N, Seemüller F, Frangou S, Möller HJ, Greil W (2008) What is the optimal serum lithium level in the long-term treatment of bipolar disorder-a review? Bipolar Disord 10:231237. CrossRef Medline

Shastry BS (1997) On the functions of lithium: the mood stabilizer. Bioessays 19:199-200. CrossRef Medline

Shin EJ, Jeong JH, Chung YH, Kim WK, Ko KH, Bach JH, Hong JS, Yoneda Y, Kim HC (2011) Role of oxidative stress in epileptic seizures. Neurochem Int 59:122-137. CrossRef Medline

Siddiqi O, Benzer S (1976) Neurophysiological defects in temperature-sensitive paralytic mutants of Drosophila melanogaster. Proc Natl Acad Sci U S A 73:3253-3257. Medline

Smolin B, Karry R, Gal-Ben-Ari S, Ben-Shachar D (2012) Differential expression of genes encoding neuronal ion-channel subunits in major depression, bipolar disorder and schizophrenia: implications for pathophysiology. Int J Neuropsychopharmacol 15:869-882. CrossRef Medline

Soehnge $\mathrm{H}$, Huang $\mathrm{X}$, Becker M, Whitley P, Conover D, Stern M (1996) A neurotransmitter transporter encoded by the Drosophila inebriated gene. Proc Natl Acad Sci U S A 93:13262-13267. Medline

Song J, Tanouye M (2007) Role for para sodium channel gene 3' UTR in the modification of Drosophila seizure susceptibility. Dev Neurobiol 67:1944-1956. CrossRef Medline

Stern M, Ganetzky B (1992) Identification and characterization of inebriated, a gene affecting neuronal excitability in Drosophila. J Neurogenet 8:157-172. Medline

Stern M, Kreber R, Ganetzky B (1990) Dosage effects of a Drosophila sodium channel gene on behavior and axonal excitability. Genetics 124:133-143. Medline

Stewart BA, Atwood HL, Renger JJ, Wang J, Wu CF (1994) Improved stability of Drosophila larval neuromuscular preparations in haemolymph-like physiological solutions. J Comp Physiol A 175: 179-191. Medline

Sun L, Gilligan J, Staber C, Schutte RJ, Nguyen V, O'Dowd DK, Reenan R (2012) A knock-in model of human epilepsy in Drosophila reveals a novel cellular mechanism associated with heatinduced seizure. J Neurosci 32:14145-14155. CrossRef Medline

Suzuki DT, Grigliatti T, Williamson R (1971) Temperature-sensitive mutations in Drosophila melanogaster. VII. A mutation (para-ts) causing reversible adult paralysis. Proc Natl Acad Sci U S A 68:890-893. Medline

Tanouye MA, Wyman RJ (1980) Motor outputs of giant nerve fiber in Drosophila. J Neurophysiol 44:405-421. Medline

Torroja L, Packard M, Gorczyca M, White K, Budnik V (1999) The Drosophila beta-amyloid precursor protein homolog promotes synapse differentiation at the neuromuscular junction. J Neurosci 19:7793-7803. Medline
Trout WE, Kaplan WD (1970) A relation between longevity, metabolic rate, and activity in shaker mutants of Drosophila melanogaster. Exp Gerontol 5:83-92. Medline

Ueda A, Wu CF (2006) Distinct frequency-dependent regulation of nerve terminal excitability and synaptic transmission by IA and IK potassium channels revealed by Drosophila Shaker and Shab mutations. J Neurosci 26:6238-6248. CrossRef Medline

Ueda A, Grabbe C, Lee J, Palmer RH, Wu CF (2008) Mutation of Drosophila focal adhesion kinase induces bang-sensitive behavior and disrupts glial function, axonal conduction and synaptic transmission. Eur J Neurosci 27:2860-2870. CrossRef Medline

Vezzani A, French J, Bartfai T, Baram TZ (2011) The role of inflammation in epilepsy. Nat Rev Neurol 7:31-40. CrossRef Medline

Wang JW, Wu CF (1996) In vivo functional role of the Drosophila hyperkinetic beta subunit in gating and inactivation of Shaker $\mathrm{K}+$ channels. Biophys J 71:3167-3176. CrossRef Medline

Wang JW, Wu CF (2010) Modulation of the frequency response of Shaker potassium channels by the quiver peptide suggesting a novel extracellular interaction mechanism. J Neurogenet 24:6774. CrossRef Medline

Wang JW, Humphreys JM, Phillips JP, Hilliker AJ, Wu CF (2000) A novel leg-shaking Drosophila mutant defective in a voltage-gated $\mathrm{K}(+)$ current and hypersensitive to reactive oxygen species. $J$ Neurosci 20:5958-5964. Medline

Wang L, Zhang L, Zhao X, Zhang M, Zhao W, Gao C (2013) Lithium attenuates IFN-beta production and antiviral response via inhibition of TANK-binding kinase 1 kinase activity. J Immunol 191: 4392-4398. CrossRef Medline

Warmke J, Drysdale R, Ganetzky B (1991) A distinct potassium channel polypeptide encoded by the Drosophila eag locus. Science 252:1560-1562. Medline

Wei H, Qin ZH, Senatorov VV, Wei W, Wang Y, Qian Y, Chuang DM (2001) Lithium suppresses excitotoxicity-induced striatal lesions in a rat model of Huntington's disease. Neuroscience 106:603-612. CrossRef

Williamson RL (1982) Lithium stops hereditary shuddering in Drosophila melanogaster. Psychopharmacology (Berl) 76:265-268. Medline

Williamson RLM (1971) The isolation and study of two mutants affecting motor activity in Drosophila melanogaster. In: Zoology. University of British Columbia: Vancouver.

Wu CF, Wong F (1977) Frequency characteristics in the visual system of Drosophila: genetic dissection of electroretinogram components. J Gen Physiol 69:705-724. Medline

Wu CF, Ganetzky B, Jan LY, Jan YN, Benzer S (1978) A Drosophila mutant with a temperature-sensitive block in nerve conduction. Proc Natl Acad Sci U S A 75:4047-4051. Medline

Yanagita T, Maruta T, Uezono Y, Satoh S, Yoshikawa N, Nemoto T, Kobayashi H, Wada A (2007) Lithium inhibits function of voltagedependent sodium channels and catecholamine secretion independent of glycogen synthase kinase- 3 in adrenal chromaffin cells. Neuropharmacology 53:881-889. CrossRef Medline

Yao WD, Wu CF (1999) Auxiliary Hyperkinetic beta subunit of K+ channels: regulation of firing properties and $\mathrm{K}+$ currents in Drosophila neurons. J Neurophysiol 81:2472-2484. Medline

Yu FH, Catterall WA (2003) Overview of the voltage-gated sodium channel family. Genome Biol 4:207. Medline

Yudkoff M, Daikhin Y, Nissim I, Lazarow A, Nissim I (2001) Ketogenic diet, amino acid metabolism, and seizure control. J Neurosci Res 66:931-940. CrossRef Medline

Yuskaitis CJ, Mines MA, King MK, Sweatt JD, Miller CA, Jope RS (2010) Lithium ameliorates altered glycogen synthase kinase-3 and behavior in a mouse model of fragile $X$ syndrome. Biochem Pharmacol 79:632-646. CrossRef Medline

Zhai RG, Hiesinger PR, Koh TW, Verstreken P, Schulze KL, Cao Y, Jafar-Nejad H, Norga KK, Pan H, Bayat V, Greenbaum MP, Bellen HJ (2003) Mapping Drosophila mutations with molecularly defined P element insertions. Proc Natl Acad Sci U S A 100:10860-10865. CrossRef Medline 